\title{
Sonic Hedgehog Signaling Is a Positive Oligodendrocyte Regulator during Demyelination
}

\author{
Julien Ferent, ${ }^{1}$ Céline Zimmer, ${ }^{2}$ Pascale Durbec, ${ }^{2}$ Martial Ruat, ${ }^{1 *}$ and Elisabeth Traiffort ${ }^{1 \star}$ \\ ${ }^{1}$ Laboratory of Neurobiology and Development Centre National de la Recherche Scientifique (CNRS) Unité Propre de Recherche-3294, Institute of \\ Neurobiology Alfred Fessard IFR2118, Signal Transduction and Developmental Neuropharmacology Team, 91198 Gif-sur-Yvette, France, and ${ }^{2}$ Institut de \\ Biologie du Développement de Marseille Luminy, CNRS Unité Mixte de Recherche-6216, 13288 Marseille, France
}

The morphogen Sonic Hedgehog (Shh) controls the generation of oligodendrocyte (OLs) during embryonic development and regulates OL production in adulthood in the cortex and corpus callosum. The roles of Shh in CNS repair following lesions associated with demyelinating diseases are still unresolved. Here, we address this issue by using a model of focal demyelination induced by lysolecithin in the corpus callosum of adult mice. Shh transcripts and protein were not detected in control animals but were upregulated in a timedependent manner in the oligodendroglial lineage within the lesion. We report an increased transcription of Shh target genes suggesting a broad reactivation of the Shh pathway. We show that the adenovirus-mediated transfer of Shh into the lesioned brain results in the attenuation of the lesion extent with the increase of OL progenitor cells (OPCs) and mature myelinating OL numbers due to survival, proliferation, and differentiation activities as well as the decrease of astrogliosis and macrophage infiltration. Furthermore, the blocking of Shh signaling during the lesion, using its physiological antagonist, Hedgehog interacting protein, results in a decrease of OPC proliferation and differentiation, preventing repair. Together, our findings identify Shh as a necessary factor playing a positive role during demyelination and indicate that its signaling activation stands as a potential therapeutic approach for myelin diseases.

\section{Introduction}

Overcoming remyelination defect represents a major challenge in the field of myelin disorders. Remyelination involves the generation of new mature oligodendrocytes (OLs) deriving from OL progenitor cells (OPCs) (Franklin and ffrench-Constant, 2008; Nishiyama e $t$ al., 2009). In response to demyelination, OPCs are recruited to the lesion site, proliferate, migrate, and rapidly fill the demyelinated area. Promoting myelin repair could be achieved by favoring either the recruitment of endogenous OPCs and/or their maturation since the lack of differentiation appears as a key element accounting for inefficient remyelination. It is thus important to uncover the molecular mechanisms regulating cell differentiation in the lesion. The first step of remyelination involves the reactivation of quiescent OPCs and re-expression of several developmental genes (Franklin and ffrench-Constant, 2008), consecutive to the acute injury-induced changes in microglia and

Received July 12, 2012; revised Nov. 14, 2012; accepted Nov. 28, 2012.

Author contributions: J.F., M.R., and E.T. designed research; J.F., C.Z., and E.T. performed research;J.F., C.Z., P.D., M.R., and E.T. analyzed data; J.F., M.R., and E.T. wrote the paper.

J.F. is supported in part by a Direction Générale de l'Armement (DGA) and an Association pour la Recherche sur le Cancer (ARC) fellowship. This work was supported by grants from Association Française contre les Myopathies and La Ligue contre le Cancer, Comité de I'Essonne et des Yvelines to M.R. We thank Drs. B. Zalc for plp-GFP mouse and C.D. Stiles and J.A. Alberta for Olig1 antibody; M. Lefebvre-Roque for helpful discussions and expert technical assistance in the early phase of this study; and Dr. S. O'Regan for critical reading of the manuscript.

${ }^{*} M . R$. and E.T. contributed equally to this work.

The authors declare no competing financial interests.

Correspondence should be addressed to either Elisabeth Traiffort or Martial Ruat, UPR-3294, Laboratory of Neurobiology and Development, Institute of Neurobiology Alfred Fessard IFR2118, 1 Avenue de la Terrasse, 91198 Gif-sur-Yvette, France, E-mail: Elisabeth.Traiffort@inaf.cnrs-gif.fr or ruat@inaf.cnrs-gif.fr.

DOI:10.1523/JNEUROSCI.3334-12.2013

Copyright $\odot 2013$ the authors $\quad 0270-6474 / 13 / 331759-14 \$ 15.00 / 0$ astrocytes, sources of growth factors such as platelet-derived growth factor (PDGF) and fibroblast growth factor (Williams et al., 2007). The LINGO-1, Notch, and canonical Wnt pathways were recently shown to negatively regulate OPC maturation and impede repair (Fancy et al., 2010; Huang et al., 2011), whereas retinoid $\mathrm{X}$ receptor gamma signaling is proposed to be a positive regulator of endogenous OPC differentiation and remyelination (Huang et al., 2011).

During development, the secreted molecule Sonic Hedgehog (Shh) is required for the specification of a first wave of OPCs originating in the ventral regions of the spinal cord and forebrain through the induction of genes encoding the basic helix-loop-helix proteins, Olig1 and Olig2 (Fuccillo et al., 2006). In the adult brain, Shh signaling is still active (Pascual et al., 2005; Traiffort et al., 2010). $\mathrm{Shh}^{+}$cells have been notably detected in GABAergic and cholinergic neurons (Traiffort et al., 1999; 2001; Charytoniuk et al., 2002a). Shh signaling is required for the establishment of the adult stem cell niches (Charytoniuk et al., 2002b; Lai et al., 2003; Machold et al., 2003) and migration of neuroblasts (Angot et al., 2008). Brain delivery of Shh increases the number of OPCs and premyelinating OLs expressing NG2 and the proteolipid protein (PLP) isoform DM20 in the normal cerebral cortex and corpus callosum (Loulier et al., 2006). Upregulation of Shh and its receptor Patched (Ptc), promoted by the administration of interferon- $\beta$, was suggested to overcome the Notch signaling inhibitory effects in models of immune and nonimmune-mediated demyelination (Mastronardi et al., 2004). Along the same lines, the recovery from chronic demyelination by thyroid hormone therapy was linked to a potent induction of oligodendrogenesis suggested to be related to the increase of Shh expression (Harsan et al., 2008). 
Here, we investigated the status and role of Shh signaling in remyelination by using lysolecithin (LPC)-induced focal demyelination in wild-type or plp-GFP transgenic mice. We identify Shh expression and the transcriptional activation of the pathway during remyelination. We show that adenovirus-mediated transfer of Shh protects from demyelination and favors the regenerative process by modulating the inflammatory response and stimulating OPC proliferation and survival and myelin formation. Finally, Shh loss of function provides evidence for considering the morphogen as a necessary positive factor during myelin repair.

\section{Materials and Methods}

Animal. All procedures were performed according to the European Communities Council Directive (86/806/EEC) for the care and use of laboratory animals. Six- to eight-week-old plp-GFP (Spassky et al., 2001; Le Bras et al., 2005) or OF1 male mice were used. Animals were housed under standard conditions with access to water and food ad libitum on a normal $12 \mathrm{~h}$ light/dark cycle.

Focal demyelination. The LPC-induced demyelination was adapted from a described protocol (Nait-Oumesmar et al., 1999). Animals were injected unilaterally into the right corpus callosum at the following stereotaxic coordinates (to the bregma): anteroposterior (AP) $+1 \mathrm{~mm}$, lateral $+1 \mathrm{~mm}$, dorsoventral (DV) $-1.7 \mathrm{~mm}$. Control animals received the vehicle solution $(0.9 \% \mathrm{NaCl})$. Mice were killed at different survival time points: 4 or 5 (peak of OPC recruitment), 7 (intermediate state), 10 (onset of OPC differentiation), and 15 (remyelination step) days postlesion $(\mathrm{dpl})$.

Adenoviral vector injection. Ad-huShh $8 \times 10^{7}$ and Ad-mHip $15 \times 10^{7}$ plaques forming units or the corresponding quantities of Ad-Control that include GFP placed under internal ribosomal entry site (Loulier et al., 2006; Angot et al., 2008; Horn et al., 2012) were injected into the right lateral ventricle $(\mathrm{LV})$ at the following stereotaxic coordinates (to the bregma): $\mathrm{AP}+0.2 \mathrm{~mm}$, lateral $+0.8 \mathrm{~mm}$, DV $-2.5 \mathrm{~mm}$.

$\mathrm{BrdU}$ treatment. For subventricular zone (SVZ)-derived cell tracing, mice received four intraperitoneal injections of bromodeoxyuridine (BrdU) as described previously (Charytoniuk et al., 2002a, b) 24 h before LPC administration.

Histological procedures. Frontal sections $(16 \mu \mathrm{m})$ from frozen brains were processed as described previously (Loulier et al., 2006; Angot et al., 2008). Primary antibodies were as follows: mouse Ki67 (1/300; BD Pharmagen), rat anti-BrdU antibody (1/200, clone BU1/75, ICR1; Harlan Sera-Lab), mouse CC1 (1/500; Calbiochem), mouse GFAP (1/400; Millipore), rabbit Olig1 (gift from Drs. C.D. Stiles and J.A. Alberta), goat Olig2 (1/100; Santa Cruz Biotechnology), rabbit Olig2 (1/1000; Millipore), rabbit 167Ab Shh (1/600; Traiffort et al., 2001), rat PDGFR $\alpha$ (1/400; BD Pharmagen), and chicken GFP (1/200; Aves Laboratory). Microglia was detected using a biotinylated-isolectin B4 staining (1/100; Sigma). The secondary antibodies were goat anti-mouse Alexa 546 (Invitrogen); goat anti-rabbit Alexa 555 (Life Technologies); donkey antigoat Alexa 546 (Life Technologies), goat anti-mouse FITC (Sigma); donkey anti-sheep, anti-mouse, or anti-rabbit Alexa 488 (Millipore); Cy3- or Cy5-conjugated antibodies (Jackson ImmunoResearch); Dylight649-streptavidine (1/200; Jackson ImmunoResearch); and goat anti-chicken Alexa 488 (1/200; Jackson ImmunoResearch). Cell nuclei were visualized with DAPI (Vector Laboratories). Triple immunofluorescence was performed as in Magalon et al. (2012). Immunofluorescent signals were detected by a conventional epifluorescence microscope (Leica Microsystems) or scanned for optic sections with an apotomeequipped microscope (Zeiss). For in situ hybridization (ISH) experiments, fragments corresponding to bases 3381-601 for Gli2 (Hughes et al., 1997; GenBank accession: BC085190) and 3715-4888 for Gli3 (Thien et al., 1996; GenBank accession: BC145445) were amplified by PCR from mouse brain cDNA, subcloned into pGEM-4Z, and sequenced before riboprobes synthesis. Ptc, Smo, Gli1, DM20, and MBP riboprobes were synthesized as previously described (Traiffort et al., 1999, 2001; Loulier et al., 2006). For Luxol Fast Blue (LFB) staining, slices were stained with $0.5 \% \mathrm{LFB}$, cleared, dehydrated, and mounted.
Quantification and statistical analysis. The demyelination surface in LPC-induced demyelination of wild-type or plp-GFP mice and cell counting were evaluated using the ImageJ software. Antigen colocalizations were considered within one apotome optical section. Immunofluorescent or ISH-positive cells were counted on three or more nonadjacent sections per mouse and averaged for each mouse; cell counts are presented as the mean of at least four mice and the SE was calculated between each mouse. Cells displaying an ISH signal within the lesions were counted once the extent of the demyelination had been established based on the decrease of plp-GFP fluorescence or LFB staining on adjacent sections. This area has been measured for each lesion on two nonadjacent sections per mouse $(n=5)$ and expressed in square millimeters. Statistical analysis was performed using the unpaired bilateral Student's $t$ test. Statistical significance was considered for $p<0.05$.

\section{Results}

\section{Increased Sonic Hedgehog in remyelinating brain lesions}

To visualize and characterize the brain remyelination, we induced LPC-mediated focal demyelination in the corpus callosum of adult plp-GFP transgenic C57BL/6 mice (Spassky et al., 2001; Le Bras et al., 2005) and performed analysis at 4, 7, and $10 \mathrm{dpl}$. In this model, most OLs degenerate in the lesion and remyelination proceeds in a stereotypic sequence of OPC recruitment peaking at day 5 and OPC differentiation starting around day 10 (Franklin and ffrench-Constant, 2008). Demyelination was easily visualized by the lack of GFP expression in the callosal white matter at the lesion site 4 and $7 \mathrm{dpl}$ (Fig. 1). As expected, no lesion was observed in any other brain regions of the same animal or of vehicle-treated animals. The LPC-induced lesions contained numerous Ki67+ proliferating cells (Fig. $1 A, B$ ) reflecting the recruitment of OPCs (Franklin and ffrench-Constant, 2008). We analyzed the populations of OPCs and OLs by performing immunohistochemistry experiments with the monoclonal antibody $\mathrm{CC} 1$, which is specific to mature OLs and a polyclonal antibody directed against the transcription factor Olig2, which is expressed by OPCs and mature OLs in LPC-demyelinated and healthy corpus callosum of plp-GFP mice at $7 \mathrm{dpl}$ when the repair process is ongoing (Fig. 1C). As expected, short chains of Olig2 ${ }^{+} / \mathrm{CC}^{+} /$ plp-GFP ${ }^{+}$cells were detected in the vehicle-treated corpus callosum, whereas disorganized Olig ${ }^{+} / \mathrm{CC}^{+}$(mature OLs), but also Olig ${ }^{+} / \mathrm{CC} 1^{-}$(OPCs) cells were observed in the demyelinated area likely reflecting the repair process.

Cells expressing Shh transcripts were identified in an area overlapping the LPC-induced demyelinated area of the corpus callosum at $4 \mathrm{dpl}$ (Fig. $2 \mathrm{~A}, \mathrm{~B}$ ). Shh peptides were evident in cells localized in lesions induced in animals at $4 \mathrm{dpl}, 7 \mathrm{dpl}$, or $10 \mathrm{dpl}$ (Fig. 2D,E), but were also observed in regions neighboring the lesion (Fig. 2F). Analysis of cell densities within the LPC-lesioned areas indicated that the highest number of Shh-positive cells was observed at $4 \mathrm{dpl}\left(699 \pm 107 \mathrm{Shh}^{+}\right.$cells $\left./ \mathrm{mm}^{2}\right)$, then decreased at $7 \mathrm{dpl}\left(383 \pm 61 \mathrm{Shh}^{+}\right.$cells $\left./ \mathrm{mm}^{2}\right)$, and stayed at a similar level at $10 \mathrm{dpl}\left(340 \pm 42 \mathrm{Shh}^{+}\right.$cells $\left./ \mathrm{mm}^{2}\right)$. Shh transcripts and peptides were neither observed in the corpus callosum of vehicle-treated mice (Fig. $2 B, F$ ), nor in the contralateral callosal white matter of LPC-treated animals. Altogether these observations demonstrate that Shh peptides are specifically upregulated in remyelinating brain lesions.

\section{Shh is expressed in the OL lineage during remyelination of adult brain}

In the LPC-lesioned areas at $4 \mathrm{dpl}$, we found that $90 \pm 6 \%$ of cells expressing Shh transcripts coexpressed Olig2, indicating that the major source of Shh is the OL lineage (Fig. 2C). In contrast, we did not detect any $\mathrm{GFAP}^{+}$astrocytes expressing Shh transcripts 



Figure 1. LPC-induced demyelination in the plp-GFP transgenic line. $A, B$, Visualization of GFP ( $g r e e n)$ in frontal brain sections of vehicle- and LPC-treated animals immunostained for Ki67 (red). C, Triple immunolabeling for GFP, CC1, and Olig2 in rostral coronal brain sections of an adult mouse treated with LPC. Both the LPC-injected and the contralateral corpus callosum of the same animal are shown. The lesion site, delineated by the weak or absent GFP expression that reflects the decrease in plp expression and thus $0 \mathrm{~L} \mathrm{survival,} \mathrm{displays} \mathrm{CC}^{+} / 0 \mathrm{lig} 2^{+}$mature $0 \mathrm{Ls}$ and $\mathrm{CC} 1{ }^{-} / 0$ lig2 ${ }^{+}$ OPC, which express low levels of GFP compared with the high levels detected within the same cell populations in the contralateral corpus callosum. cc, Corpus callosum; $C \mathrm{C}$, cerebral cortex. Scale bars: $A, B, 200 \mu \mathrm{m} ; C, 100 \mu \mathrm{m}$

(data not shown). Using immunohistofluorescence, we observed that Shh-immunoreactive signals were forming dense puncta closely surrounding the cell nucleus, but also at a distance from the nuclei suggesting that Shh peptides may have been secreted (Fig. 2F). Interestingly, these signals were colocalized with plpGFP fluorescence around the cell nuclei as shown at $7 \mathrm{dpl}$ (Fig. $2 F$ ) confirming that cells derived from the OL lineage constitute a source of Shh within the lesion. Shh-immunoreactive signals were visible in cells expressing the OPC marker PDGFR $\alpha$ (Nishiyama et al., 2009; Fig. 2G). We determined that $70 \pm 6 \%$ of $\mathrm{Shh}^{+}$cells coexpressed GFP and $36 \pm 5 \%$ of $\mathrm{Shh}^{+}$cells were PDGFR $\alpha^{+}$(Fig. 2H). Altogether, these data demonstrate that cells of the whole OL lineage including OPCs are the major source of Shh transcription and production in remyelinating lesions of the corpus callosum.
Shh signaling pathway is transcriptionally induced during remyelination

During development or in the adult brain, Shh has been shown to induce the upregulation of target genes encoding the Gli transcription factors; the Shh receptor Ptc; and Smo, a key transducer acting downstream of Ptc (Akazawa et al., 2004; Fuccillo et al., 2006; Traiffort et al., 2010). Therefore, we investigated whether these key components of the Shh pathway were upregulated following the lesion. We performed ISH experiments in demyelinated and control brains at $10 \mathrm{dpl}$, when precursor differentiation is initiated (Fig. 3A,B). Ptc, Smo, Gli1, and Gli2 were upregulated in LPC-treated animals in an area overlapping the demyelinated area visualized by the absence of GFP fluorescence (Fig. 3C). In contrast, in sections from control animals, transcript expression was not detected or was present at a very low level. 

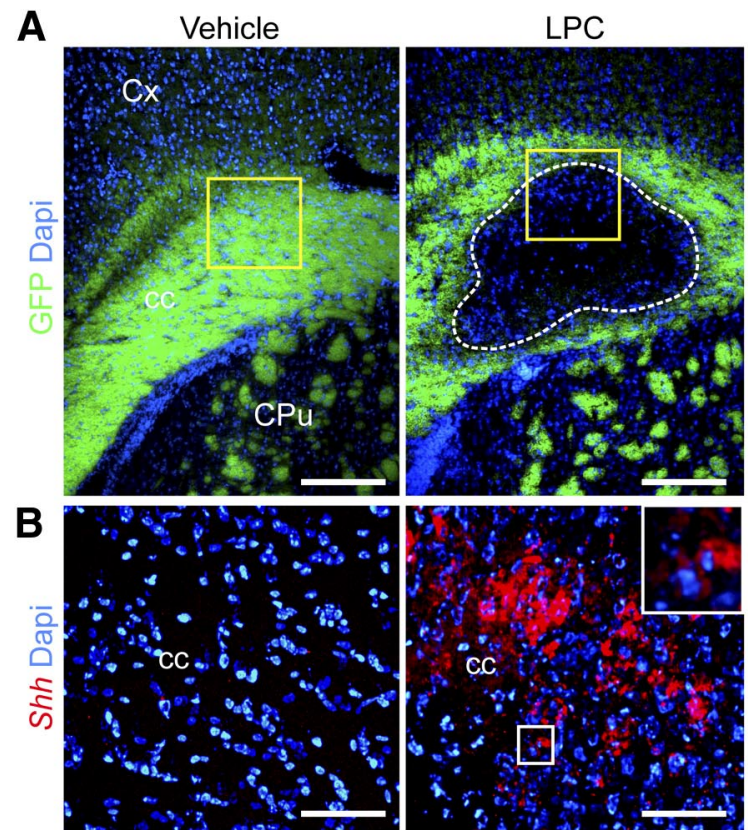

Olig2 DAP|

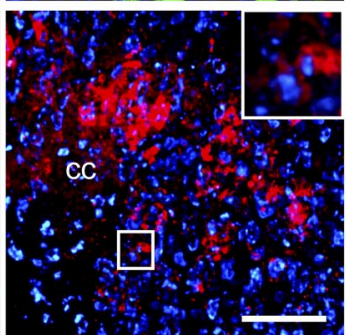

Olig2 Shh

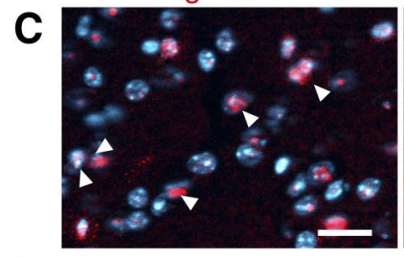

F
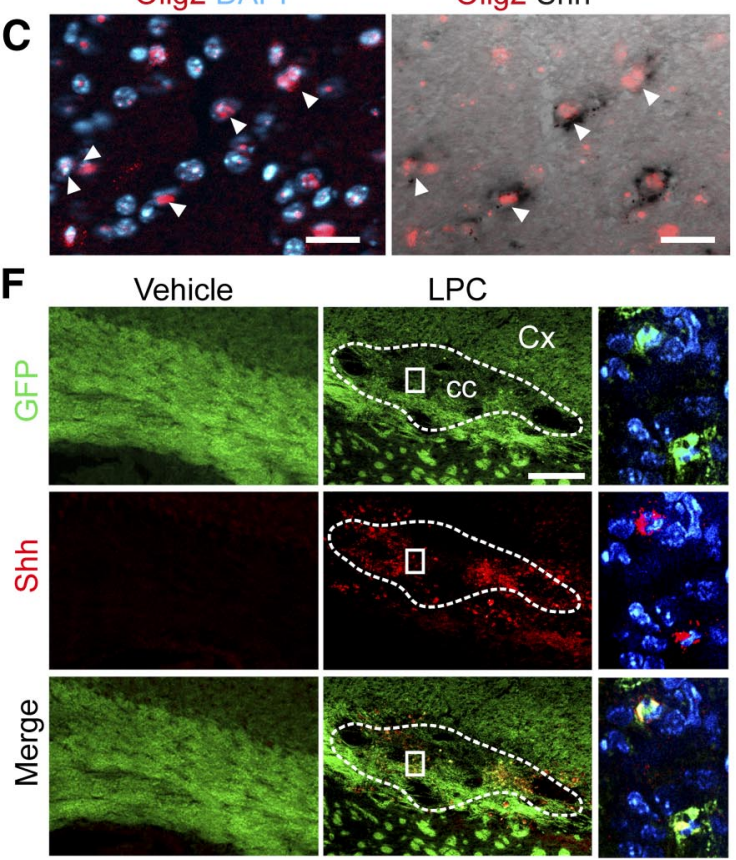

LPC

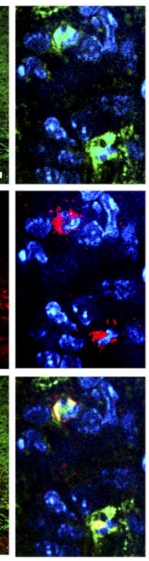

D

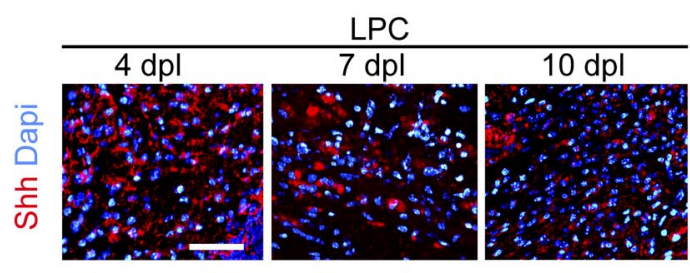

\section{$E$}

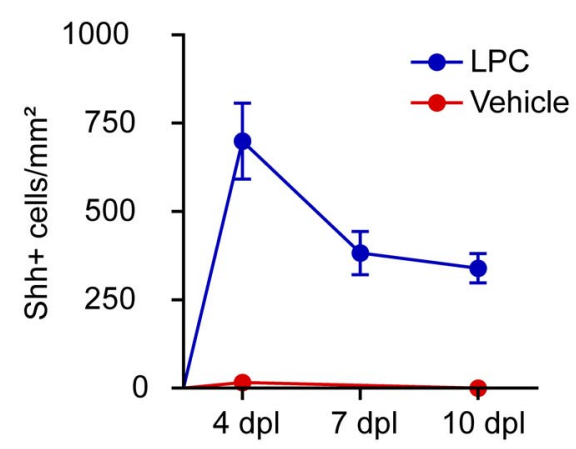

G

H
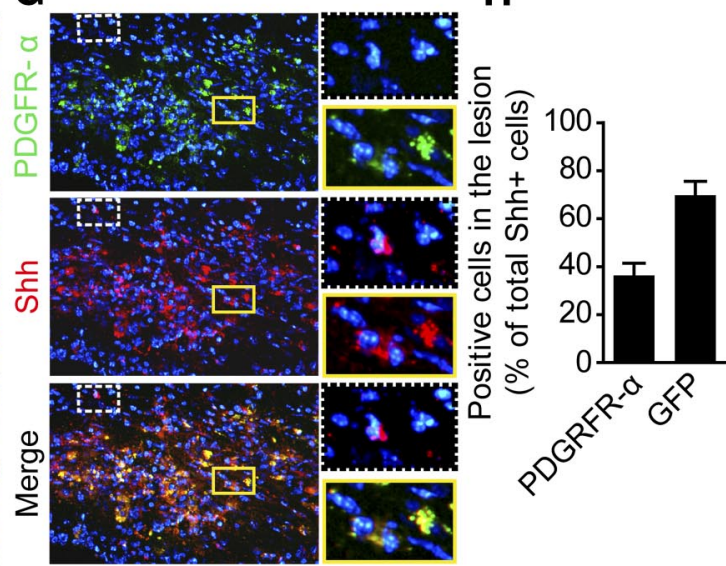

Figure 2. Shh is expressed in the OL lineage during demyelination of adult brain. $A$, Endogenous GFP fluorescence (green) analyzed by confocal microscopy in frontal brain sections from plp-GFP mice treated $4 \mathrm{~d}$ earlier with vehicle or LPC. B. Fluorescent ISH experiment performed on adjacent sections (at a level corresponding to the area boxed in yellow in $A$ ). Shh ${ }^{+}$signals (red) are detected in the demyelinated corpus callosum of the LPC-treated animal, but not in the control. Magnification of the area boxed in white is shown. C, At $4 \mathrm{dpl}$, Shh transcripts are detected within the lesion in cells coexpressing Olig2 (white arrowhead). D, Immunofluorescent labeling of Shh protein (red) at $4 \mathrm{dpl}$ in vehicle-treated and $4 \mathrm{dpl}, 7 \mathrm{dpl}$, or $10 \mathrm{dpl}$ in LPC-treated animals. E, Number of Shh ${ }^{+}$ cells in the above conditions compared with levels observed in the vehicle-treated mice. $F$, At $7 \mathrm{dpl}$, Shh immunolabeling (red) is colocalized with the endogenous GFP fluorescence (green) associated with cells in the lesion, delineated by the white dotted line. $\mathbf{G}, \mathrm{A}$ population of $\mathrm{Shh}^{+}$cells also coexpresses PDGFR $\alpha$ (green) in the lesion. The dotted-line box shows one Shh ${ }^{+}$cell, which does not express PDGFR $\alpha$, whereas the yellow box highlights two cells expressing both Shh and PDGFR $\alpha$. $\boldsymbol{H}$, Quantification of the percentage of Shh ${ }^{+}$cells coexpressing PDGFR $\alpha$, the $p l p$-GFP reporter. Values are the mean \pm SEM of three to four animals in each group. cc, Corpus callosum; $C$, cerebral cortex; CPu, caudate-putamen. Scale bars: $A, F, 100 \mu \mathrm{m} ; \boldsymbol{B}, \mathbf{D}, 50 \mu \mathrm{m} ; C, 20 \mu \mathrm{m}$.

Quantitative analysis indicated a significant upregulation for Gli1, Gli2, Ptc, and Smo transcripts (Fig. 3D). In contrast, Gli3 transcripts were not observed in the lesion, while Gli3 ${ }^{+}$cells were detected in other brain areas (data not shown).

Then, we evaluated in the LPC-induced lesion the phenotype of cells expressing Gli1, considered as the main Shh target gene, and Smo, which showed the highest induction. First, we investigated if both Smo and Gli1 transcripts were expressed in the OL population as we previously showed for Shh. Colocalization of Olig2 was observed in $24 \pm 7 \%$ of Gli1 ${ }^{+}$cells at $5 \mathrm{dpl}$, demonstrating that an Shh signaling response is triggered in OPCs at the earliest steps of repair. Then, this colocalization increased to $66 \pm$ $10 \%$ at 10 and $15 \mathrm{dpl}$ showing that a large population of differentiating OLs are responding to Shh (Fig. $4 A, C$ ). We evaluated whether Smo-expressing cells were Olig2 ${ }^{+}$as well, and found a notable difference. Olig ${ }^{+}$cells represented $15 \pm 2 \%$ of the total 
A
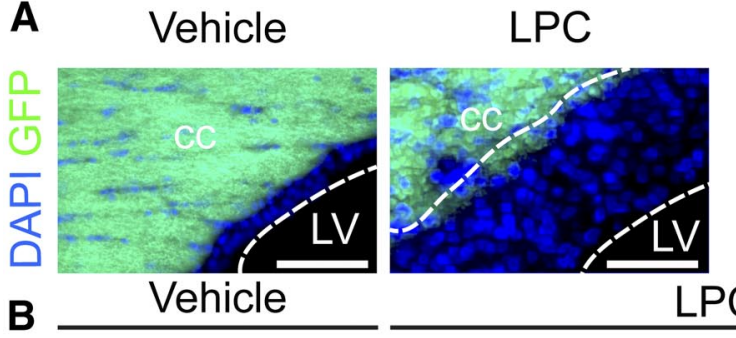

B
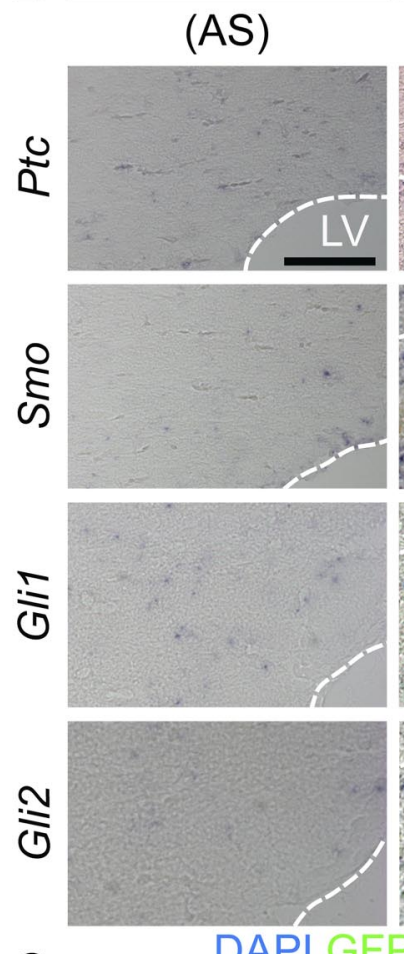

C
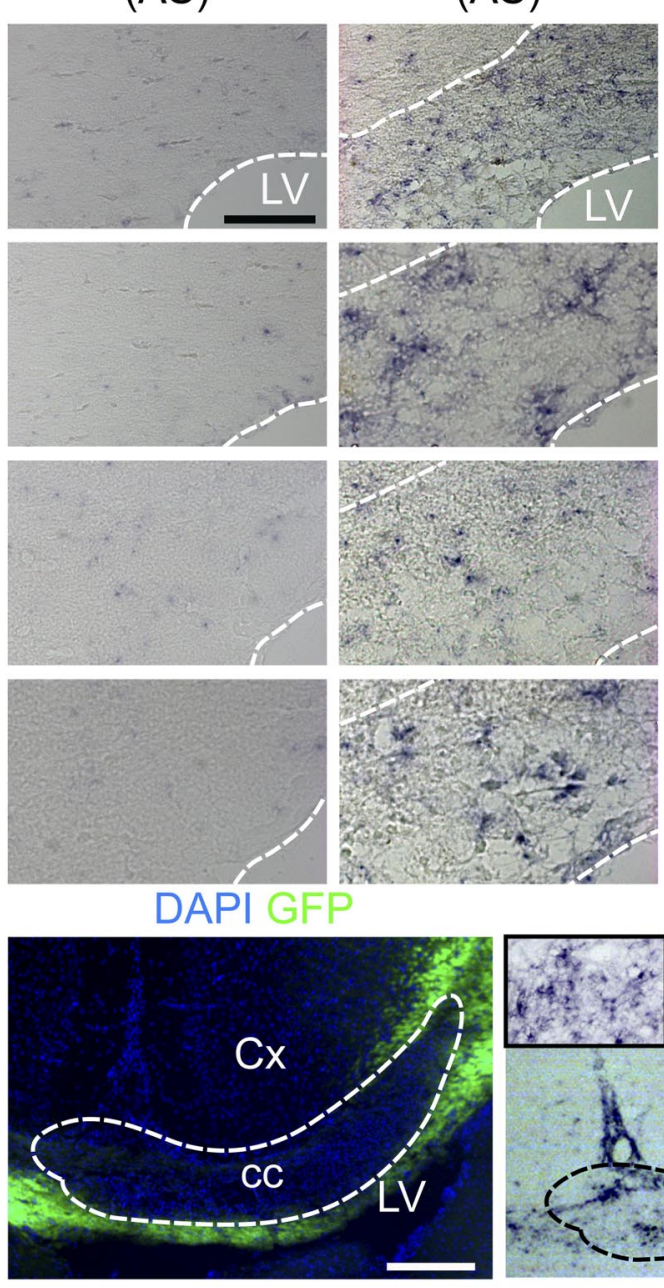

Injection site

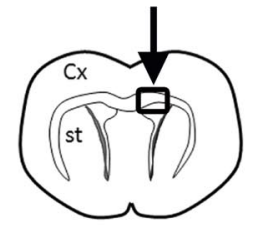

PC

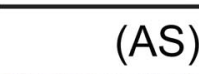

(S)
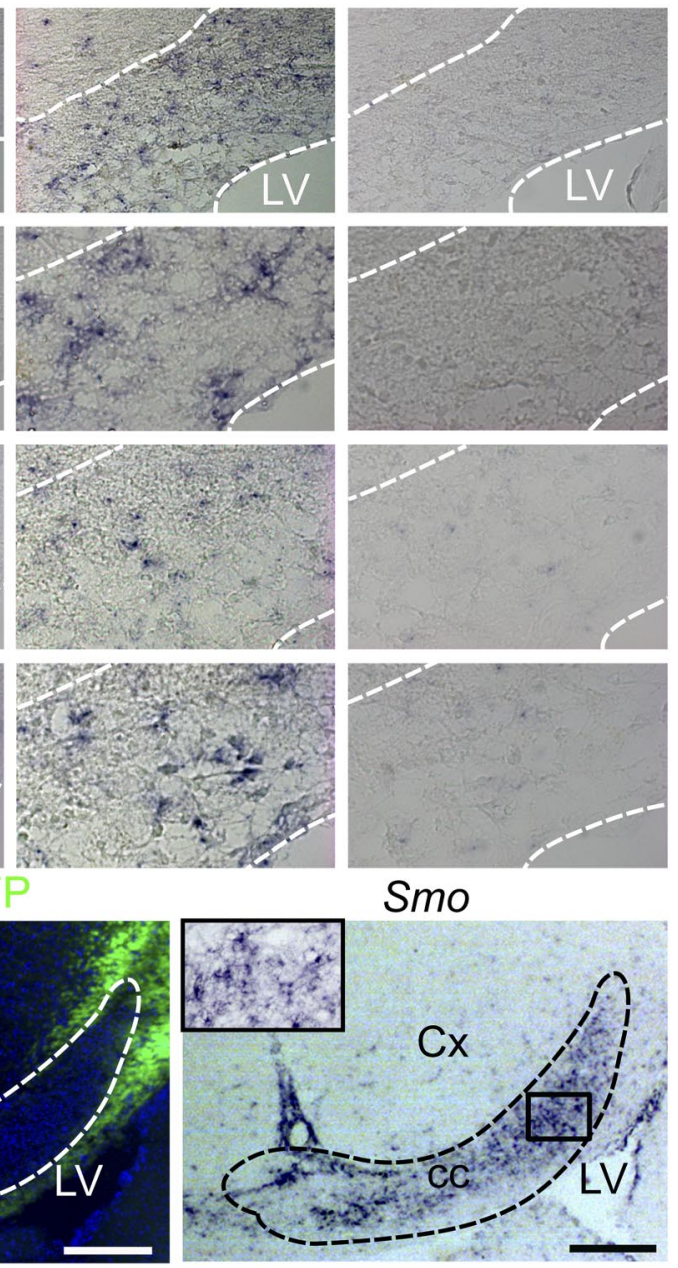

D

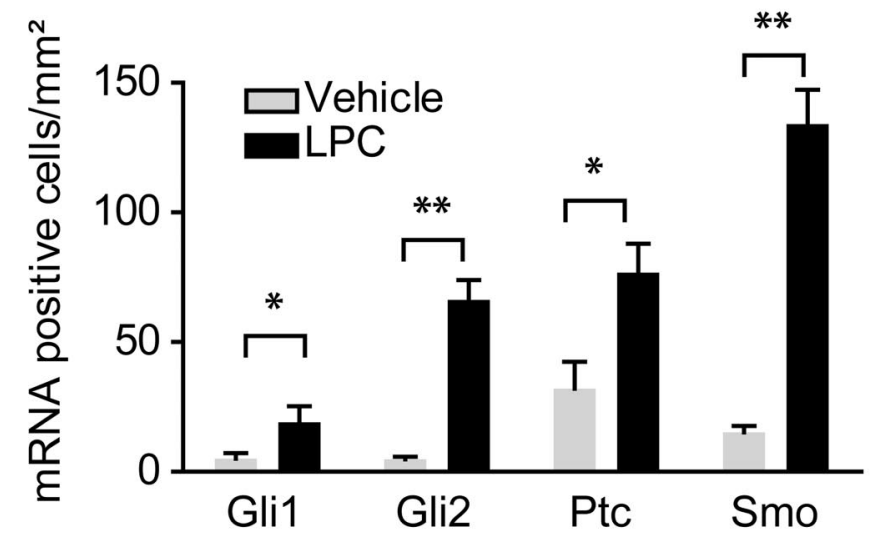

Figure 3. Upregulation of the Shh signaling pathway in the model of focal demyelination. $A$, Right, GFP fluorescence in the region of the corpus callosum where LPC or the vehicle was injected as indicated on the brain scheme (10 dpl). $\boldsymbol{B}$, ISH signals in the callosal region shown in $A$ were obtained using the indicated antisense (AS) or sense ( $S$ ) riboprobes. The lesion extent is highlighted by the white dotted line. C, Low magnification of a coronal brain section derived from an LPC-treated mouse and hybridized using number of cells expressing Smo at $5 \mathrm{dpl}$ and this percentage only slightly increased at later stages $(28 \pm 10 \%)$ (Fig. $4 D, G$ ). These data indicated that a rather limited population of $\mathrm{Smo}^{+}$cells belongs to the OL lineage and that Smo is also expressed by other cell populations within the lesion.

The corpus callosum of LPC-treated mice displayed a marked increase in the number of $\mathrm{GFAP}^{+}$reactive astrocytes and also in cells expressing the isolectin-B4 (IB4), a marker for both ramified (nonactivated) and activated microglial cells in the lesion and the surrounding tissues, suggesting the presence of macrophage and reactive glia, respectively (Ayoub and Salm, 2003; Williams et al., 2007). We thus investigated whether a subset of cells, which upregulate Gli1 and Smo, corresponded to astroglial cells. At 5, 10, and 15 $\mathrm{dpl}$, only a low percentage (1-12\%) of Gli1- or Smo-expressing cells was GFAP ${ }^{+}$ cells (Fig. $4 B, C, E, G$ ). These data suggest that reactive astrocytes are not the main target of the Shh pathway after demyelination. Remarkably, we found that $57 \pm 2 \%$ of $\mathrm{Smo}^{+}$cells were $\mathrm{IB} 4{ }^{+}$at $5 \mathrm{dpl}$, and this percentage did not significantly change at later stages (Fig. 4F, G). Therefore, microglial cells represented half of the population of $\mathrm{Smo}^{+}$cells in the lesion demonstrating that these cells participate in the Shh pathway response.

Altogether, these data indicate that key genes involved in the Shh signaling pathway are upregulated within the lesion upon focal demyelination in the corpus callosum and two major components of the Shh pathway, Gli1 and Smo, are mainly regulated in OLs and microglia, respectively.

\section{Adenovirus-mediated transfer of Shh attenuates LPC-induced demyelination through OPC differentiation and OL protection}

We have previously showed that Shh delivery in the LV through its direct injection or after administration of an adeno-

\footnotetext{
the Smo AS riboprobe (right). The extent of the lesion (white line) indicated by the absence of GFP fluorescence (left) overlaps the Smo ISH signal (black line) and was measured to quantify the levels of transcript upregulation. D, Histogram showing the number of cells in the lesion that express Gli1, Gli2, Ptc, and Smo transcripts in vehicle-treated (gray bars) or LPC-treated (black bars) animals. The values are expressed per square millimeter of lesion and are the mean \pm SEM of four to five animals (3-6 slices per animal). cc, Corpus callosum; $C x$ cerebral cortex; St, striatum. Scale bars: $\boldsymbol{A}, \boldsymbol{B}, 50 \mu \mathrm{m} ; \boldsymbol{C}, 200$ $\mu \mathrm{m}\left({ }^{*} p<0.05 ;{ }^{* *} p<0.001\right)$.
} 

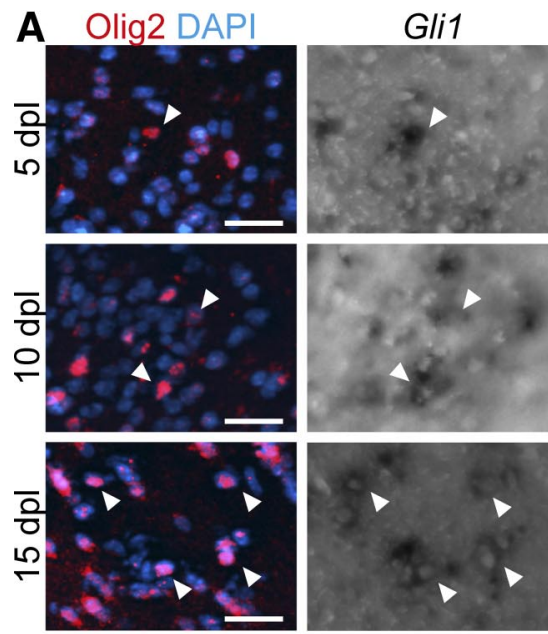

B GFAP DAPI

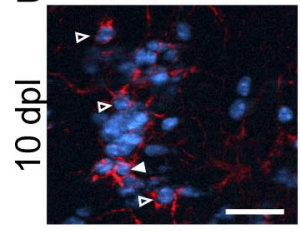

C
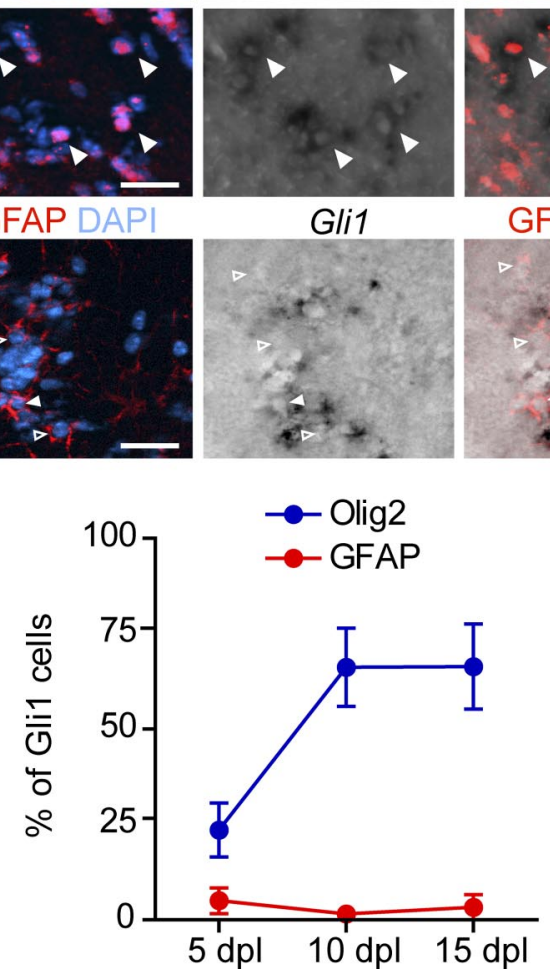

Gli1

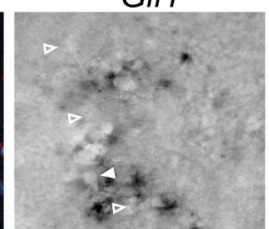

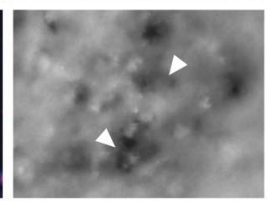

Olig2 Gli1
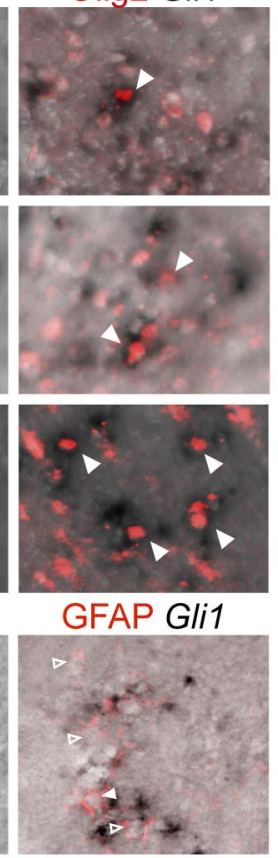

G
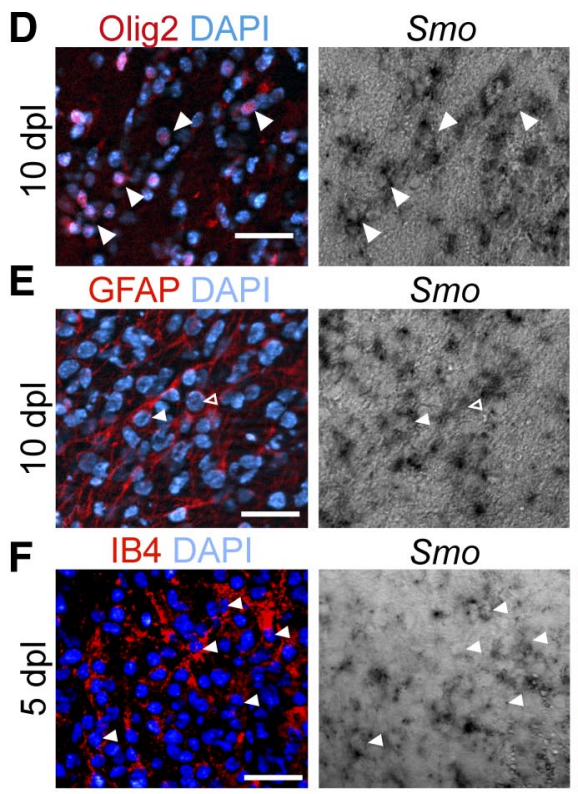

Figure 4. Identification of the phenotype of Shh-responding cells over the length of remyelination. $A, B, G$ Gi7 transcripts are expressed in a subset of Olig2-positive cells within LPC-induced lesion. C, Quantification of the percentage of Gli7-positive cells, which express Olig2 and GFAP in the demyelinated area by 5, 10, and $15 \mathrm{dpl}$. D-F, Expression of Smo transcripts in subsets of 0lig2, GFAP, and IB4-positive cells within remyelinating areas at the indicated time points after the LPC-induced lesion. G, Quantification of the percentage of Smo-positive cells, which express Olig2, GFAP, and IB4 in the lesion by 5, 10, and $15 \mathrm{dpl}$. White plain arrowheads show double-positive cells, whereas white empty arrowheads show single immunopositive cells. The values are the mean \pm SEM of three to four animals in each group. Scale bars: $50 \mu \mathrm{m}$.

viral vector bearing the gene encoding Shh (Ad-huShh), induced an increase of NG2 proliferating cells and the expression of oligodendrocyte markers in various brain areas including the corpus callosum (Loulier et al., 2006). As the above observations suggested that endogenous Shh signaling participates in OPC differentiation, we assessed whether the prolonged administration of Shh could affect the demyelination/remyelination process in vivo. Therefore, Ad-huShh or the corresponding control (AdControl) adenoviral vectors were stereotaxically injected into the right LV of OF1 mice two days after LPC injection into the right corpus callosum to investigate the potential regenerative effects of Shh. Animals were killed 5, 10, or $15 \mathrm{dpl}$ for further analysis (Fig. 5A).

First, we visualized the cells that were infected upon injection of the viral vectors into the LV by using GFP as a reporter. The viral vectors we have previously developed and used in the present work were set up as bicistronic vectors that include GFP placed under the internal ribosomal entry site (Loulier et al., 2006). As expected (Yoon et al., 1996; Benraiss et al., 2001;
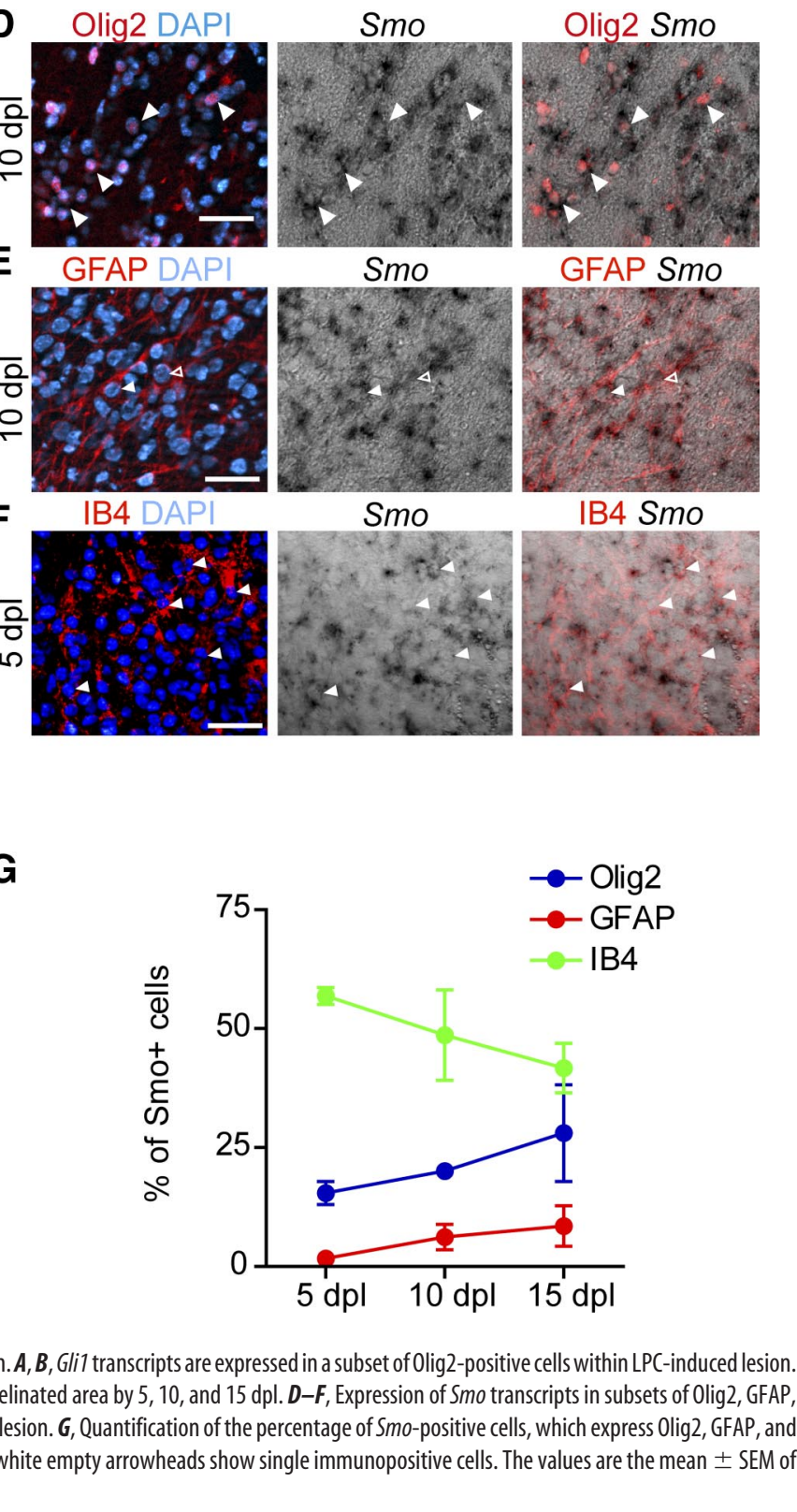

Loulier et al., 2006; Angot et al., 2008), at 10 dpl, GFP immunostaining led us to visualize a high GFP expression in cells lining the ventricle, which reflects the infection of ependymal cells in both Ad-huShh and Ad-Control animals (Fig. 5B). In addition, we found a high Shh signal mostly in the ependymal cell layer associated with $\mathrm{GFP}^{+}$cells of Ad-huShh but not Ad-Control mice (Fig. 5B). In contrast, we detected almost no $\mathrm{GFP}^{+}$cells in the lesion of both animal groups. A strong Shh immunoreactivity was detected in the lesion of Ad-huShh animals compared with Ad-Control animals (Fig. 5C). These data are consistent with the absence or the very low number of infected SVZ cells previously reported (Yoon et al., 1996; Benraiss et al., 2001; Loulier et al., 2006; Angot et al., 2008). Altogether the results indicate that the overexpression of Shh in the lesion of Ad-huShh animals is mostly related to the secretion of the protein by ependymal cells, suggesting a nonautonomous effect of the protein.

Then, we evaluated the number of Olig ${ }^{+}$-proliferating OPCs using Ki67 as a marker of cycling cells at $5 \mathrm{dpl}$, when most precursors are dividing. We found a twofold significant increase of 
A

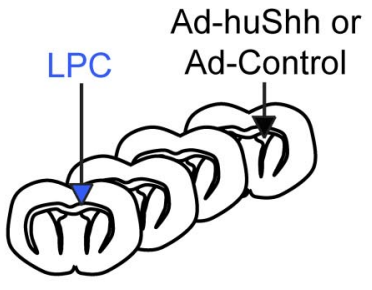

Regenerative protocol

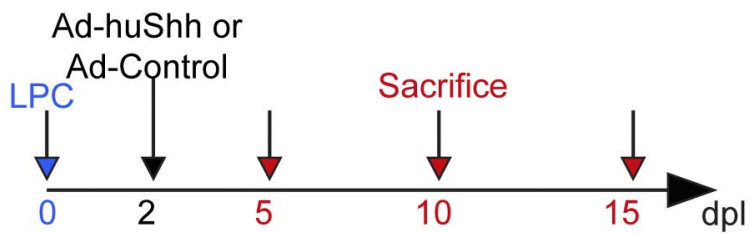

B
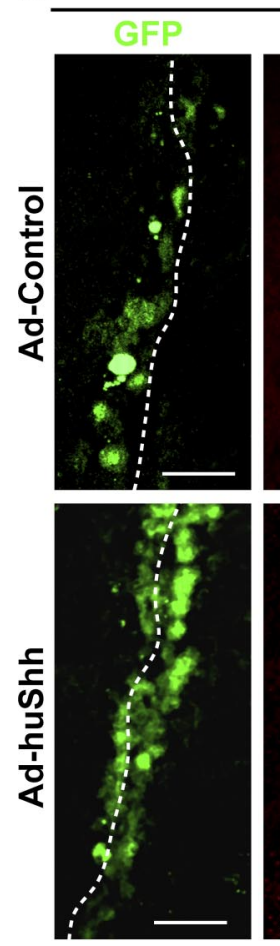

SVZ $10 \mathrm{dpl}$
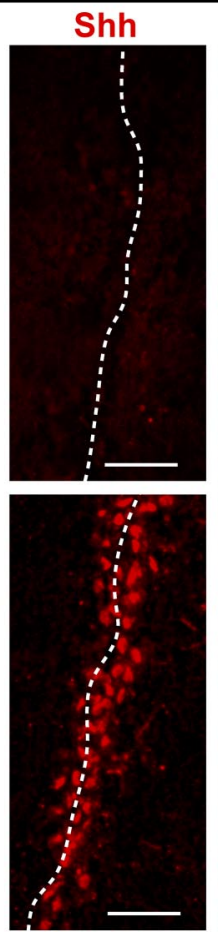

C
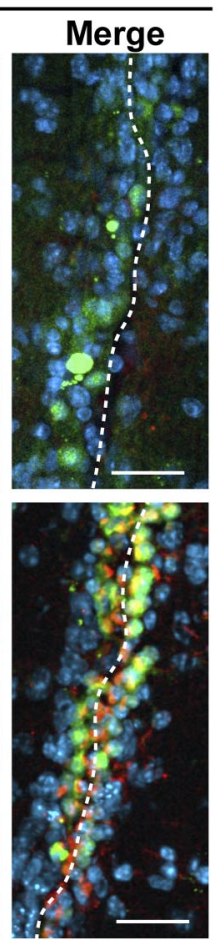

$\underline{\mathrm{C}}$

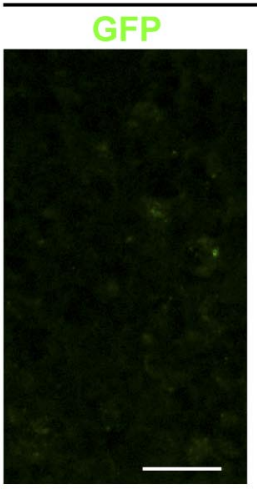

Lesioned cc $10 \mathrm{dpl}$
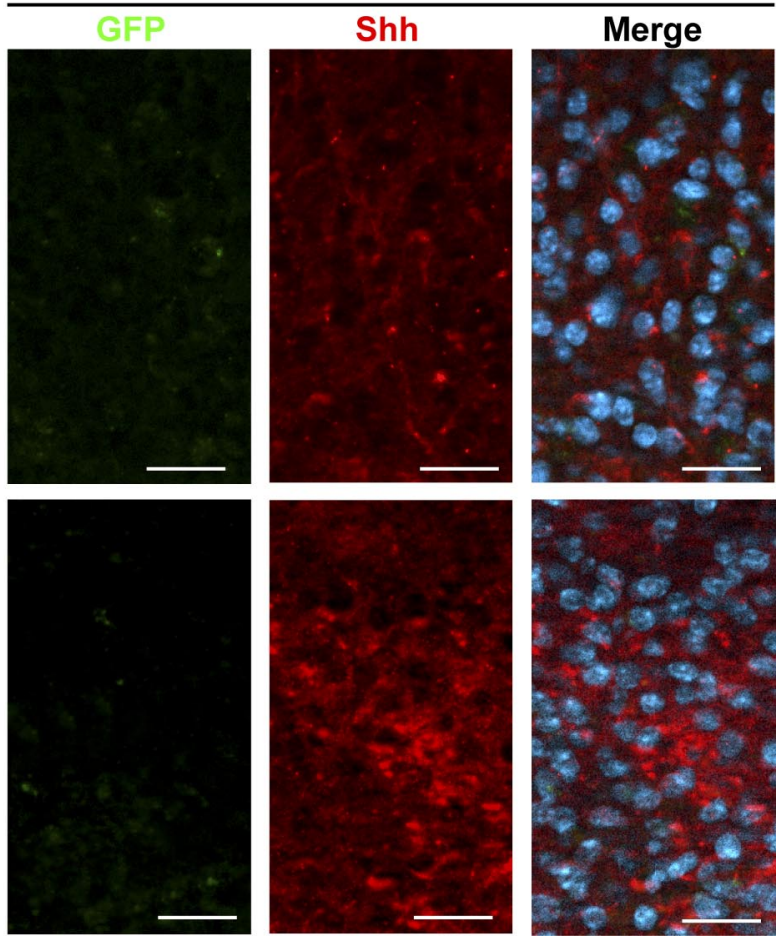

Figure 5. Identification of infected cells in the lesioned brain of mouse injected by Ad-Control or Ad-huShh adenoviruses. $A$, Scheme of the regenerative protocol. $B, C$, Immunostaining of GFP (green) expressed by the viral constructs is detected in the wall of the LV of Ad-Control or Ad-huShh-injected brains (B) but not in the LPC-induced lesion in the corpus callosum (cc) at $10 \mathrm{dpl}$ ( $\boldsymbol{C}$ ). Shh immunostaining (red) is associated mostly with the ependymal cell layer in the Ad-huShh condition and is evidenced in the lesions in both conditions, reflecting endogenous and exogenous Shh. Nuclei are stained with DAPI (blue). The white dotted line indicates the ventricular wall. Scale bars: B, C, $30 \mu \mathrm{m}$.

Ki $67^{+} /$Olig2 ${ }^{+}$cells in Ad-huShh compared with Ad-control mice $(16.6 \pm 2.6 \%$ vs $8.7 \pm 2.3 \%$; $p<0.05$; Fig. $6 A, B)$, which demonstrated that Shh overexpression enhances OPC proliferation. Then, we investigated the dynamics of OPC differentiation using several specific markers and staining. At $10 \mathrm{dpl}$, we observed a notable increase in Olig2 ${ }^{+}$OLs ( $956 \pm 99$ vs $503 \pm 83$ cells $\left./ \mathrm{mm}^{2} ; p<0.02\right)$ and $D M 20^{+}$differentiated OLs $(720 \pm 69$ vs $339 \pm 42$ cells $\left./ \mathrm{mm}^{2} ; p<0.01\right)$. We have also evaluated the fraction of differentiated $D M 20^{+}$OLs within the whole Olig2 ${ }^{+}$ OL population in Ad-huShh-compared with Ad-Control-treated animals at 5, 10, and $15 \mathrm{dpl}$ (Fig. $6 \mathrm{C}-\mathrm{G}$ ). We found that at $10 \mathrm{dpl}$, $80 \pm 4 \%$ of Olig $2^{+}$cells coexpressed DM20 in the lesion of AdhuShh animals versus only $61 \pm 2 \%$ in Ad-Control mice at $10 \mathrm{dpl}$ $(p<0.01)$. These data indicated that Ad-huShh promotes the differentiation of OPCs into differentiated OLs and that the increase of mature $\mathrm{MBP}^{+}$cells is not the result of an increased number of OPCs. In both animal groups, the demyelinated areas were visualized by LFB staining, which specifically labels the myelin fibers. To look at the regenerative potential of Shh, the lesion extent was measured in every condition, showing that even if no difference was detectable at $5 \mathrm{dpl}$, the administration of AdhuShh reduced the demyelinated area at $10 \mathrm{dpl}(0.09 \pm 0.01 \mathrm{vs}$ $\left.0.16 \pm 0.02 \mathrm{~mm}^{2} ; p<0.05\right)$ compared with the control condition
(Fig. $6 \mathrm{H}, J$ ). The number of $M B P^{+}$myelinating OLs in the lesion was also clearly increased at the same time point in the presence of Ad-huShh compared with the control vector $(1018 \pm 70$ vs $285 \pm$ 89 cells $/ \mathrm{mm}^{2} ; p<0.001 ;$ Fig. $\left.6 I, K\right)$. These data thus indicate that Shh overexpression increases first the proliferation of a subset of OPCs at $5 \mathrm{dpl}$ and then the number of differentiated OLs at 10 $\mathrm{dpl}$. These effects lead to an earlier reduction of the lesion accompanied by an increase in the number of myelinating cells.

To investigate the potential protective effect of Shh on the survival of OPCs during demyelination, we set up a second protocol, which relies on the injection of the adenovirus $2 \mathrm{~d}$ before LPC injection and analyzed the animals at 5, 10, and $15 \mathrm{dpl}$ (Fig. $7 A$ ). Evaluation of cell apoptosis using the terminal deoxynucleotidyl transferase-mediated biotinylated UTP nick end labeling (TUNEL) assay showed a reduced density of apoptotic cells in the lesion at $1 \mathrm{dpl}$ in animals that received Ad-huShh $(182 \pm 19$ vs $387 \pm 72$ cells $/ \mathrm{mm}^{2} ; p<0.05 ;$ Fig. $\left.7 B\right)$. In addition, as soon as 1 $\mathrm{dpl}$, a significantly higher density of Olig2 ${ }^{+}(538 \pm 98$ vs $145 \pm 5$ cells $\left./ \mathrm{mm}^{2}, p<0.01\right)$ and $D M 20^{+}$cells $(275 \pm 59$ vs $73 \pm 28$ cells $/ \mathrm{mm}^{2} ; p<0.02$ ) was observed in Ad-huShh versus AdControl-treated animals (Fig. 7C,F). Altogether, these data support the protective effect of Shh for both OPCs and differentiated OLs. 


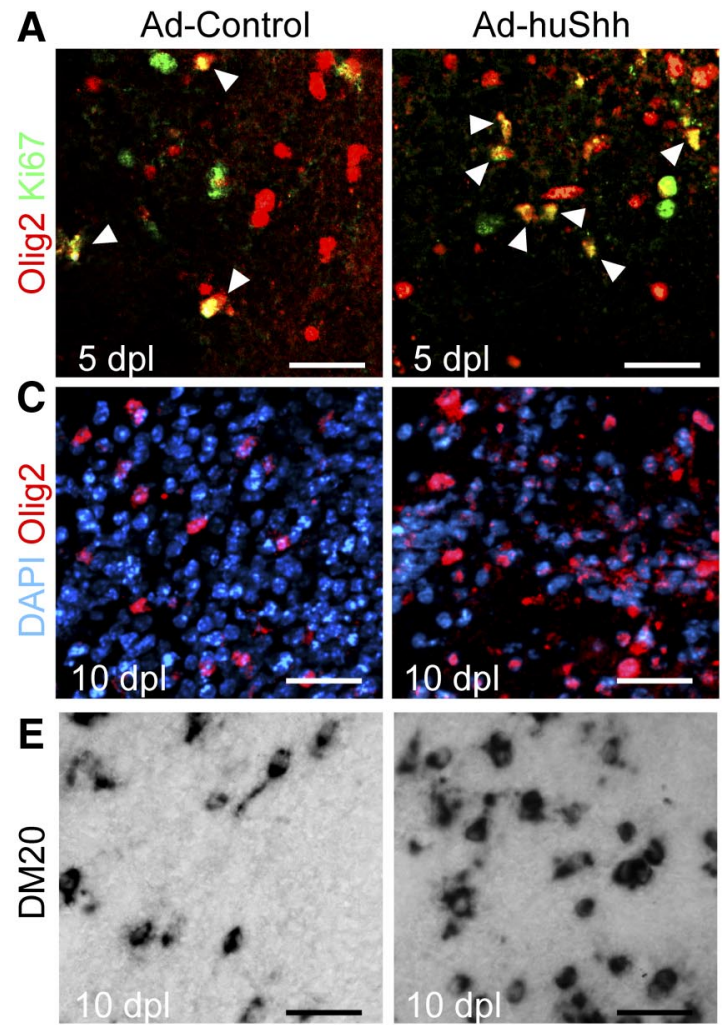

B

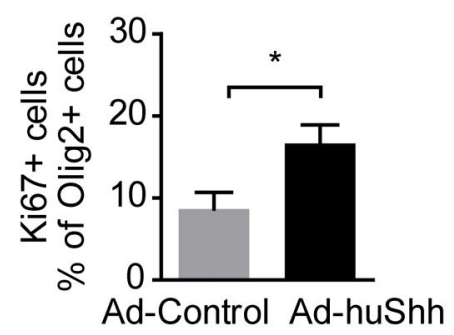

$\mathbf{F}$

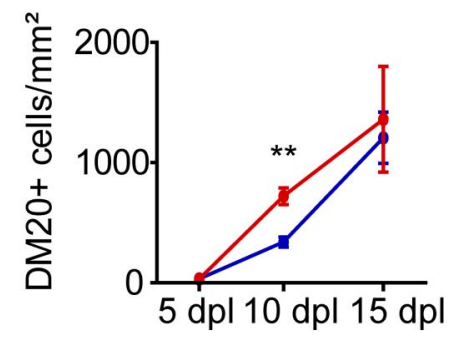

D

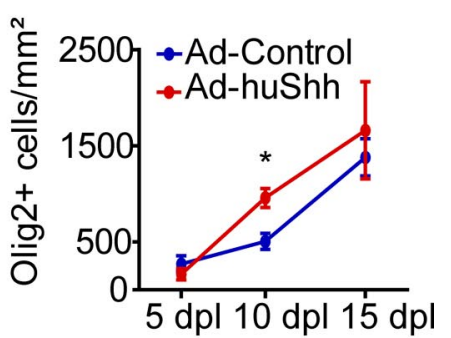

G

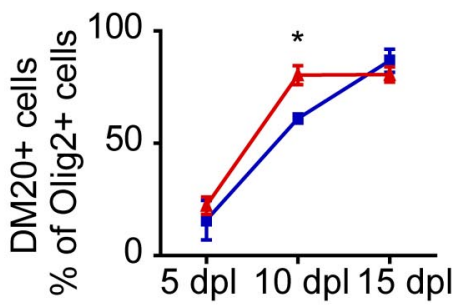

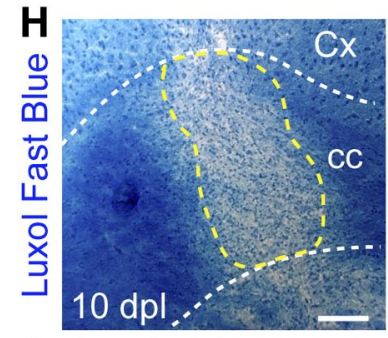
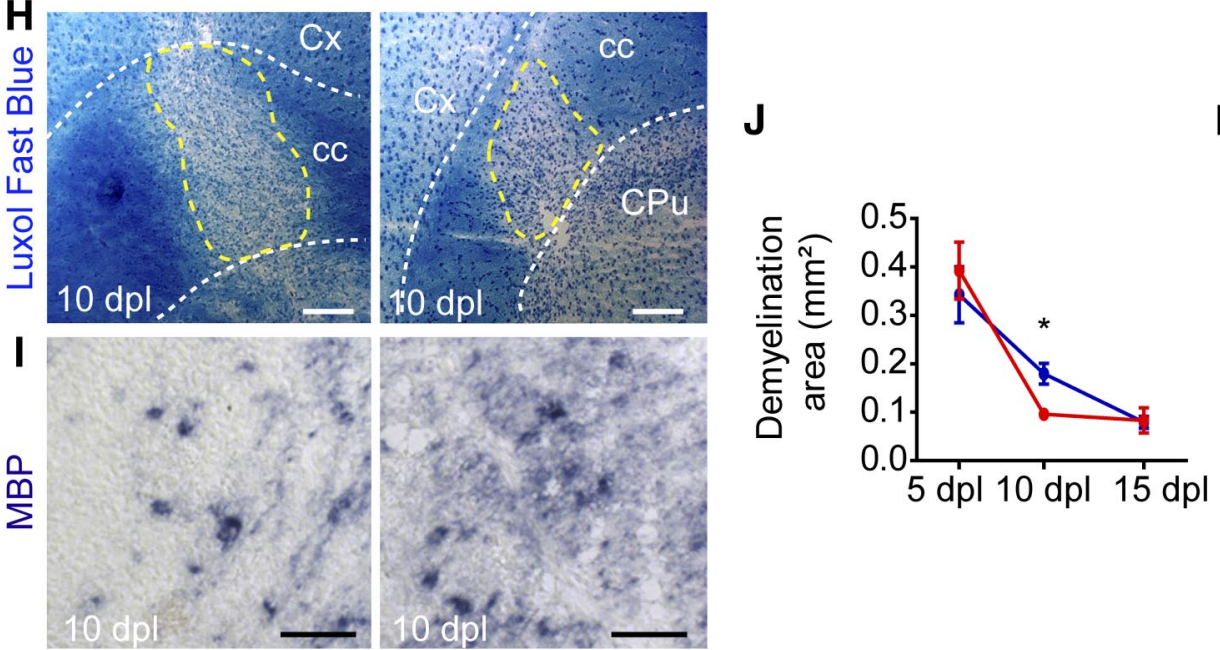

$\mathbf{K}$

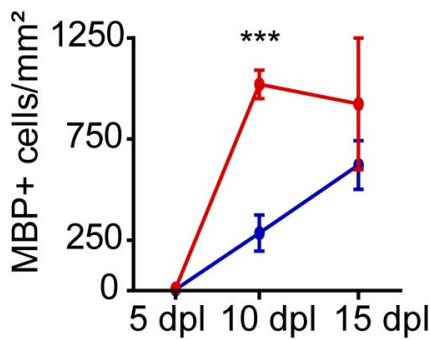

Figure 6. Adenovirus-mediated transfer of Shh in vivo markedly attenuates LPC-induced myelin loss by accelerating OPC differentiation into premyelinating $0 \mathrm{Ls}$. $\boldsymbol{A}, \boldsymbol{B}, \mathrm{Ad}$-huShh increases the proliferating 0 lig2 ${ }^{+}$cells at $5 \mathrm{dpl}$ as indicated by the quantification of Ki67/Olig2 ${ }^{+}$in both animal groups. C $-G$, A significant increase in the number of 0 lig2 ${ }^{+}$and $D M 20^{+} 0 \mathrm{Ls}$ as well as in the fraction of $D M 20^{+}$cells within the whole 0 lig ${ }^{+} 0 \mathrm{~L}$ population is seen at $10 \mathrm{dpl}$ in callosal regions compared with control-treated controls. $\boldsymbol{H}-\boldsymbol{K}, \mathrm{LFB}$ staining $(\boldsymbol{H})$ and $M B P$ expression $(\boldsymbol{I})$ are shown in the demyelinated corpus callosum at $10 \mathrm{dpl}$ in Ad-huShh and Ad-control mice. Smaller lesion areas and higher MBP expression are observed in Ad-huShh versus control animals. $\boldsymbol{J}, \boldsymbol{K}$, Quantifications of demyelinated areas and $\mathrm{MBP}^{+}$cell density in Ad-huShh and Ad-control mice at 5, 10, and 15 dpl. Values are the mean \pm SEM of four animals in each group. cc, Corpus callosum; CX, cerebral cortex; (Pu, caudate-putamen. Scale bars: $\boldsymbol{A}, \boldsymbol{C}, \boldsymbol{E}, \boldsymbol{I}, 50 \mu \mathrm{m} ; \boldsymbol{H}, 200 \mu \mathrm{m} .{ }^{*} p<0.05 ;{ }^{* *} p<0.001 ;{ }^{* * *} p<0.005$.

$\mathrm{Olig}^{+}$cells originating in the SVZ migrate to the corpus callosum and the number of these cells increases after a demyelinating lesion (Nait-Oumesmar et al., 1999; Menn et al., 2004). To investigate whether the increased number of OLs could be partly related to the rapid recruitment from the SVZ of neural progenitors specified into OPCs, BrdU pulses were performed $24 \mathrm{~h}$ before LPC injection and used to trace SVZ-cycling cells recruited to the lesion. The density of $\mathrm{BrdU}^{+} / \mathrm{Olig} 2{ }^{+}$cells observed in the lesion at 1 or $10 \mathrm{dpl}$ increased in a time-dependent manner as previously proposed (Nait-Oumesmar et al., 1999; Menn et al., 2004), but was not significantly different in Ad-huShh compared with Ad-Control animals (Fig. 7G). These data demonstrate that Shh overexpression does not increase SVZ-derived neural precursors in the lesion, but rather targets the resident population of OPCs.

At $10 \mathrm{dpl}$, in the presence of Ad-huShh, the percentage of cells containing cytoplasmic Olig1 was significantly higher compared with Ad-Control ( $88 \pm 1 \%$ vs $54 \pm 8 \%$; $p<0.01$; Fig. $7 D, E)$ indicating the Olig1 population comprises a high majority of OLs (cytoplasmic Olig1) compared with OPCs (nuclear Olig1). Such a proportion of cytoplasmic Olig $1^{+}$OLs is reached in AdControl mice only at $15 \mathrm{dpl}$ suggesting that Shh overexpression 
A

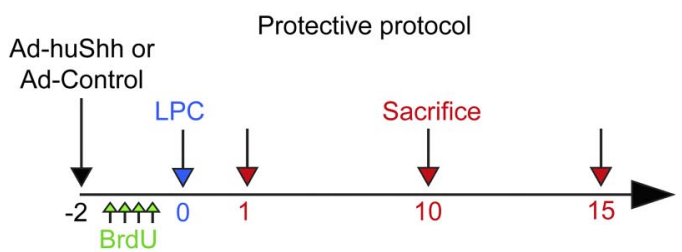

B
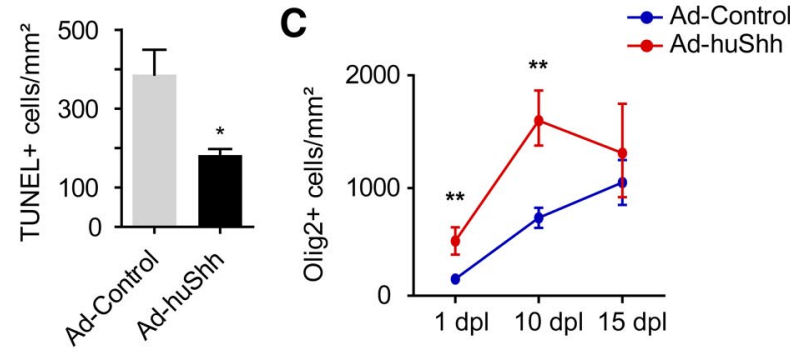

D
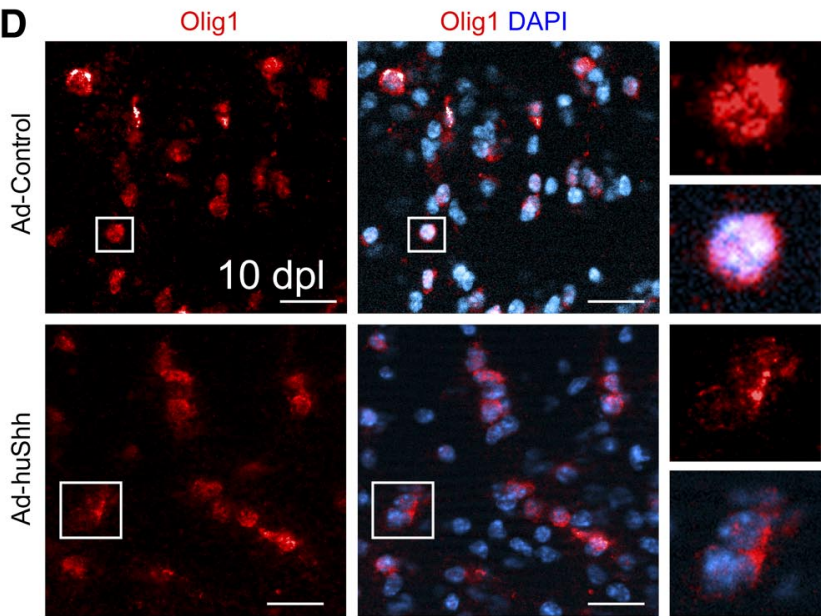

E

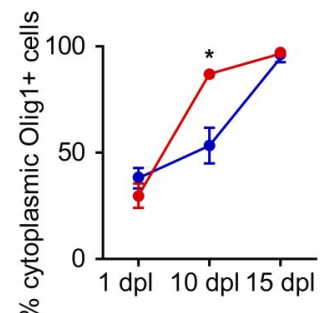

G

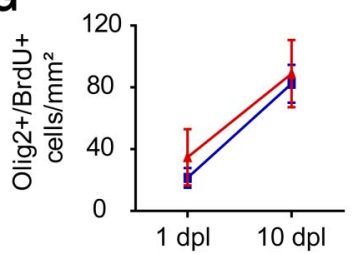

I

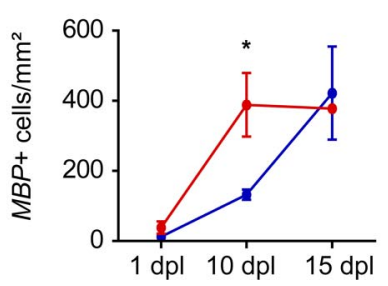

$\mathbf{F}$

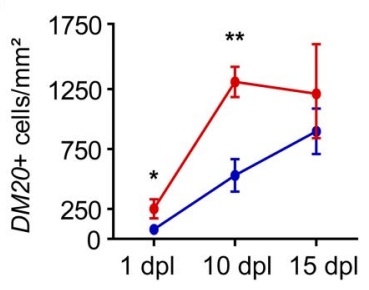

H

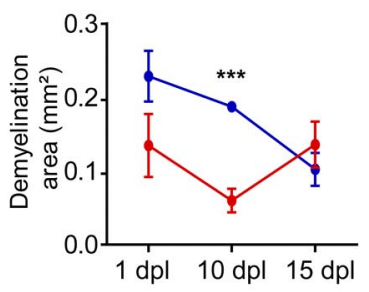

J

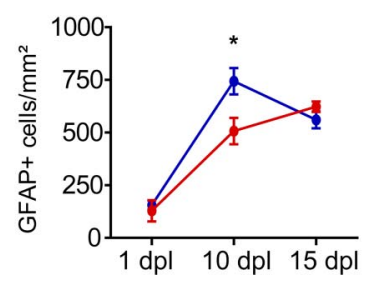

Figure 7. Protective effects of Ad-huShh during demyelination in OF1 mice. $\boldsymbol{A}$, Scheme of the protective protocol. $\boldsymbol{B}$, Transfer of Ad-huShh into the LV, $2 \mathrm{~d}$ before LPC injection in the corpus callosum is accompanied by a lower density of apoptotic cells identified by the TUNEL assay at 1 $\mathrm{dpl}$ compared with Ad-Control. C, Significant increase in the appearance of Olig2-expressing OLs at 1 and $10 \mathrm{dpl}$ is detected in callosal regions from Ad-huShh compared with Ad-Control

significantly accelerates the repair process reflected by the precocious change in Olig1 protein subcellular localization (Arnett et al., 2004). This observation is consistent with the higher density of Olig $2^{+}\left(1627 \pm 200\right.$ vs $723 \pm 93$ cells $\left./ \mathrm{mm}^{2}, p<0.01\right)$ and $D_{M} 0^{+}\left(1310 \pm 109\right.$ vs $530 \pm 136$ cells $\left./ \mathrm{mm}^{2} ; p<0.01\right)$ cells detected in Ad-huShh mice at $10 \mathrm{dpl}$ (Fig. 7C,F). Moreover, at the same time point, the density of myelinating $\mathrm{MBP}^{+}$OLs (388 \pm 116 vs $\left.132 \pm 15 \mathrm{cell} / \mathrm{mm}^{2} ; p<0.04\right)$ and the extent of the lesion visualized by the LFB staining $(0.077 \pm 0.020$ vs $0.205 \pm 0.006$; $p<0.001)$ were found significantly higher and reduced in AdhuShh animals, respectively (Fig. $7 \mathrm{H}, I$ ). Interestingly, the density of astroglial GFAP ${ }^{+}$cells was significantly decreased in the presence of Shh at $10 \mathrm{dpl}$ (Fig. $7 \mathrm{~J})$. Since Shh was present both before the lesion and during the repair process, the events observed here at $10 \mathrm{dpl}$ likely reflect both the protective and the regenerative effects of Shh. At $15 \mathrm{dpl}$, no difference was observed between Ad-huShh and Ad-Control mice indicating that a similar remyelination has occurred in the control animals (Fig. $7 E, F, H-J)$.

Shh treatment reduces inflammation and reactive astrogliosis during remyelination of the corpus callosum

Since the density of GFAP ${ }^{+}$cells was found decreased as described previously, we explored the capacity of Shh overexpression to regulate microglia and reactive astrocytes in the LPC-mediated lesion. In OF1 mice receiving Ad-huShh or Ad-Control, $2 \mathrm{~d}$ after LPC injection, the density of inflammatory cells and reactive astrocytes was evaluated after 5, 10, and $15 \mathrm{dpl}$ by IB4 and GFAP staining, respectively (Fig. $8 A-D)$. We noticed a clear increase in the size and the number of processes of astrocytes at $10 \mathrm{dpl}$, which is a known feature of reactive astrogliosis (Sofroniew, 2009). The marked downregulation of $\mathrm{GFAP}^{+}$astrocytes observed within the callosal white matter of animals treated with Ad-huShh $(340 \pm 20$ vs $647 \pm 32$ cells $\left./ \mathrm{mm}^{2} ; p<0.001\right)$ at $10 \mathrm{dpl}$ likely reflects the decrease of this astrogliosis by Shh. At $5 \mathrm{dpl}$, the number of IB $4^{+}$microglial cells in the lesion was significantly reduced by 2.5 -fold in the animals with overexpressed Shh $\left(438 \pm 62\right.$ vs $1084 \pm 145$ cells $/ \mathrm{mm}^{2} ; p<$ $0.01)$. These data revealed that the numbers of reactive astrocytes and microglia/macrophages are negatively regulated by the morphogen in a time-dependent manner, in LPC-induced lesions.

\section{Adenovirus-mediated transfer of the Shh physiological antagonist, Hedgehog interacting protein, blocks the proliferation and differentiation of OPCs and prevents tissue repair}

To investigate the effects induced by the blocking of Shh activity in the lesion in vivo, we used the adenoviral vector (Ad-mHip) bearing the gene encoding Hedgehog-interacting protein (Hip), the natural negative regulator of the $\mathrm{Hh}$ morphogen pathway (Chuang and McMahon, 1999; Coulombe et al., 2004). We have

animals. $\boldsymbol{D}$, Olig1 immunohistofluorescence detected in the LPC-induced lesion of Ad-control and Ad-huShh-treated mice. Small panels beside each picture are magnifications of a cell expressing 0 lig 1 in the nucleus (top) and in the cytoplasm (bottom), respectively. $\boldsymbol{E}$, The percentage of cells expressing 0 lig1 in the cytoplasm is higher at $10 \mathrm{dpl}$ in Ad-huShh compared with Ad-Control mice. $\boldsymbol{F}$, Significant increase in the appearance DM20-expressing $0 \mathrm{Ls}$ at 1 and $10 \mathrm{dpl}$ is detected in callosal regions from Ad-huShh compared with Ad-Control animals. G, The density of SVZ-derived BrdU ${ }^{+} / 0$ lig2 ${ }^{+}$cells is not different in Ad-huShh compared with Ad-Control mice. $\boldsymbol{H}, \boldsymbol{I}, \mathrm{An}$ increase in myelinating $0 \mathrm{Ls}$ and a decrease in the lesion extent are also observed. $\boldsymbol{J}$, The density of GFAP ${ }^{+}$astrocytes is decreased in the lesion at $10 \mathrm{dpl}$. Values are the mean \pm SEM of four animals in each group $\left({ }^{*} p<0.05 ;{ }^{* *} p<0.001\right.$; $\left.{ }^{* * *} p<0.005\right)$. Scale bars: $100 \mu \mathrm{m}$. 
previously shown that Ad-mHip produced Hip soluble form that can block Shh activity in vivo when injected in the LV (Angot et al., 2008). Ad-mHip or the corresponding control (Ad-Control) adenoviral vectors were stereotaxically injected into the right LV of OF1 mice two days before LPC injection. Animals were killed $5 \mathrm{dpl}, 10 \mathrm{dpl}$, or $15 \mathrm{dpl}$ for further analysis (Fig. 9A). First, Ad-mHip did not alter the number of apoptotic cells as shown by the absence of modification in the density of TUNEL ${ }^{+}$cells compared with Ad-Control (Fig. 9B). Thus, further blocking Shh signaling does not result in an increase of apoptotic cells. This might be related to the already high number of these cells within the lesion rather than to a possible difference in the survival effect exerted by endogenous or exogenous Shh. However, we found a twofold significant decrease in the number of proliferating $\mathrm{Ki} 67^{+} /$Olig $2^{+}$OPCs at $5 \mathrm{dpl}$ in Ad-mHip compared with Ad-control mice (5.5 \pm $1.5 \%$ vs $11.3 \pm 1.9 \%$; $p<0.05$; Fig. $9 D$ ), which demonstrated that Hip overexpression decreases OPC proliferation. The dynamics of OPC differentiation was then analyzed with the previously used specific markers and stainings. At $10 \mathrm{dpl}$, we observed a notable decrease in Olig ${ }^{+}$cells and $\mathrm{DM}_{20}{ }^{+}$differentiated OLs, which was amplified at $15 \mathrm{dpl}(139 \pm 31$ vs $1177 \pm 331$ Olig ${ }^{+}$cells $/ \mathrm{mm}^{2} ; p<0.01$; $73 \pm 20$ vs $1022 \pm 285 \mathrm{DM}^{2} 0^{+}$cells/ $\left.\mathrm{mm}^{2} ; p<0.005\right)$. The fraction of differentiated $\mathrm{DM} 20^{+}$OLs within the whole Olig2 ${ }^{+}$OL population was also significantly decreased in the presence of mHip at $15 \mathrm{dpl}$ (52 \pm 6 vs $87 \pm 1 \%$; $p<0.001$; Fig. $9 C, E-H$ ). The lesion extent determined by LFB staining was higher, while the number of $\mathrm{MBP}^{+}$myelinating OLs in the lesion was lower in Ad-mHiptreated mice at $10 \mathrm{dpl}$. These effects were again amplified at $15 \mathrm{dpl}$ $\left(0.30 \pm 0.08\right.$ vs $0.09 \pm 0.01 \mathrm{~mm}^{2}$ of lesioned tissue; $p<0.001$; $61 \pm 32$ vs $785 \pm 176 \mathrm{MBP}^{+}$cells $/ \mathrm{mm}^{2} ; p<0.002$; Fig. $\left.9 I-L\right)$. These data thus indicate that blocking of Shh activity impairs the repair process by decreasing both OPC proliferation and differentiation.

\section{Discussion}

In this study, we have investigated the role of Shh signaling in remyelination in vivo. First, in a commonly used model of LPCinduced demyelination of the corpus callosum, we showed that Shh is expressed during the onset of the demyelination process and that Shh signaling components including Gli1 and Smo are upregulated during remyelination. Second, we identified cells of the oligodendroglial lineage as the major cellular source of Shh within and around the lesion. Third, we demonstrated that Shh treatment reduces inflammation and reactive astrogliosis during remyelination of the corpus callosum and is accompanied by an increased number of OPCs and mature myelinating OLs. This effect does not reflect the increase of SVZ-derived neural precursors, but rather the proliferation, survival, and differentiation of the resident OPCs in the lesions. Finally, Shh loss of function in
LPC-induced demyelination identifies Shh as a necessary factor playing a positive role during myelin repair.

Our data provide the first evidence for the dynamic expression of Shh during remyelination and show that Sh expression within cells of the OL lineage is specific to the lesioned, but not normal, adult white matter. Since Shh protein reaches a high expression level at the peak of OPC recruitment and persists during OPC differentiation, this suggests that the endogenous activation of Shh signaling may be involved throughout both repair steps. Interestingly, the phenotypic characterization of Shhexpressing cells in the repairing tissue shows that both OPCs and more mature OLs produce Shh by $7 \mathrm{dpl}$, suggesting a massive reactivation of Shh signal. Since at this stage the differentiation of OPCs has not yet started, GFP ${ }^{+}$cells expressing Shh could correspond to mature OLs spared during the degenerative process or to cells in transition between OPCs and differentiated OLs. Here we demonstrate that oligodendroglial cells are the major source of Shh transcription in the lesion since $>90 \%$ of the Shhexpressing cells coexpress Olig2 at $4 \mathrm{dpl}$, showing the unique ability of these cells to produce and secrete the morphogen in the lesion.

Reactive astrocytes were previously proposed to produce Shh via an inflammation-dependent mechanism in the cerebral cortex in a model of acute cerebral injury (Amankulor et al., 2009) and in a mouse model of glioblastoma (Becher et al., 2008). Moreover, Shh was proposed to be upregulated in the corpus callosum astroglia and in spinal cord neurons of EAE 
A Loss of function protocol

Ad-mHip or

Ad-Control

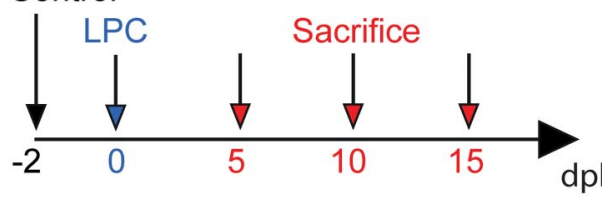

B

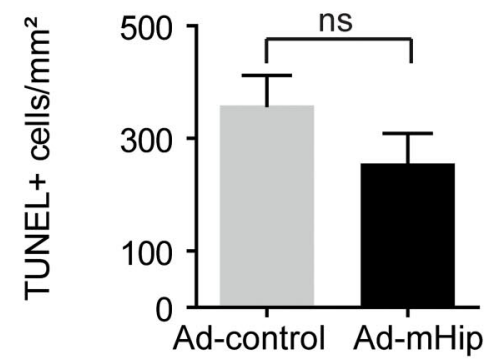

C

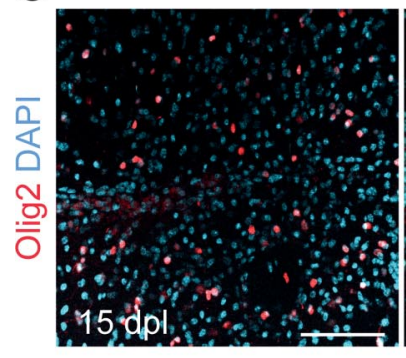

$F$

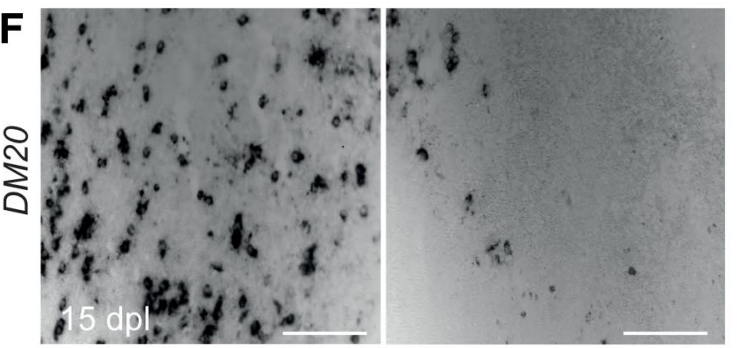

I
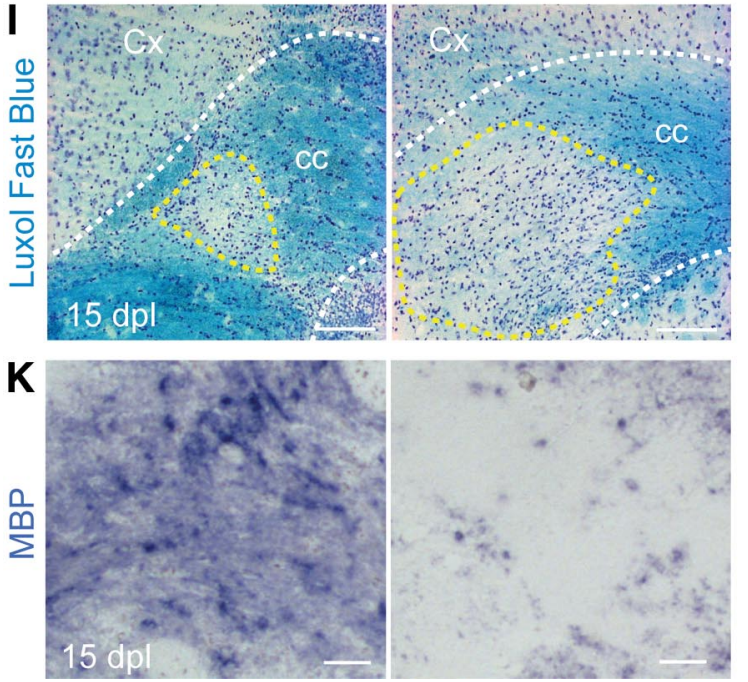

Ad-mHip
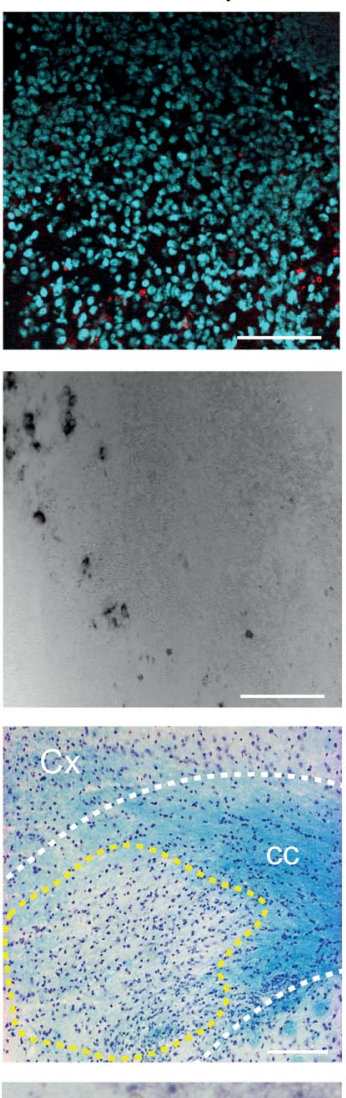

D

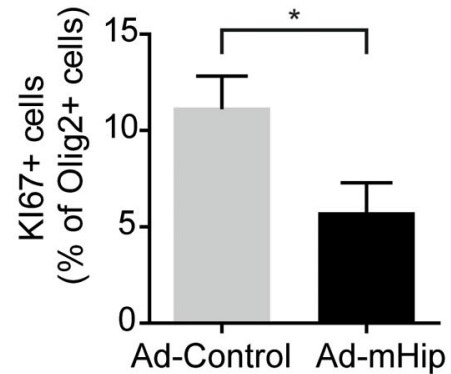

G

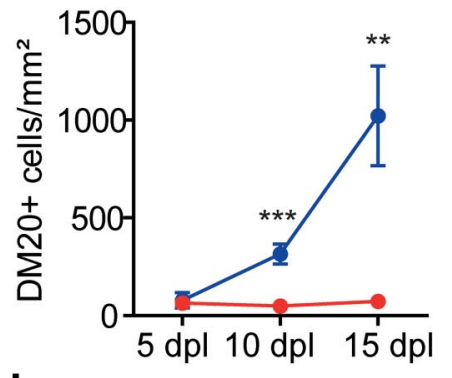

$\mathbf{J}$

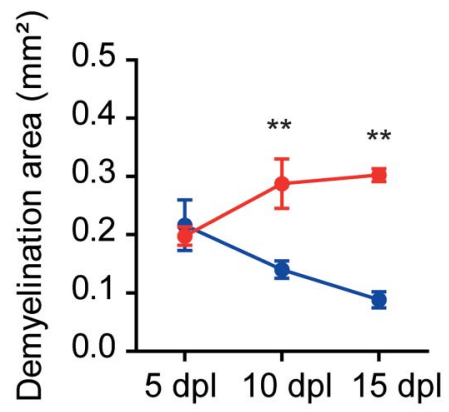

E

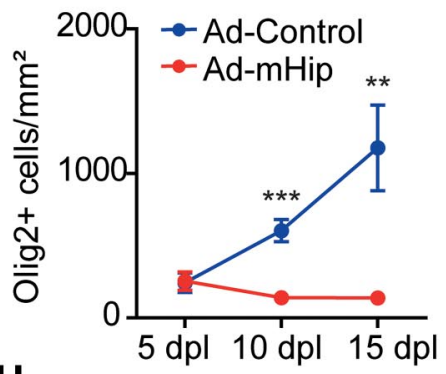

H

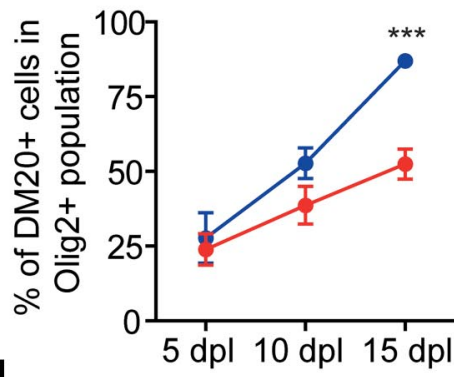

L

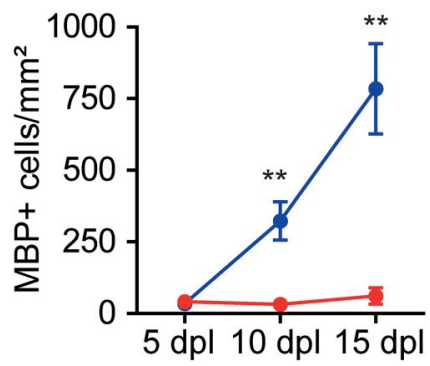

Figure 9. Overexpression of Hip, the physiological antagonist of Shh, in LPC-treated animals blocks OPC proliferation and differentiation preventing tissue repair. A, Scheme of the loss-offunction protocol. $B$, Transfer of Ad-mHip into the LV, $2 \mathrm{~d}$ before LPC injection in the corpus callosum does not modify the density of apoptotic cells identified by the TUNEL assay at $5 \mathrm{dpl}$ compared with Ad-Control. $\boldsymbol{C}-\boldsymbol{E}, \mathrm{Ad}$-mHip decreases the 0 lig2 ${ }^{+}$cells as shown on the pictures of the lesion area at $15 \mathrm{dpl}(\boldsymbol{C})$ and by the quantification of 0 lig2 ${ }^{+}$cells compared with $\mathrm{Ad}$-Control $(\boldsymbol{E})$. It also decreases proliferating 0 lig $2^{+}$cells at $5 \mathrm{dpl}$ as indicated by the quantification of Ki67/0lig2 ${ }^{+}$in both animal groups (D). $\mathbf{F}-\boldsymbol{H}, \mathrm{A}$ significant decrease in the number of $D M 20^{+} 0 \mathrm{Ls}(10$ and $15 \mathrm{dpl}$, G) illustrated by the picture of the lesion at $15 \mathrm{dpl}(\boldsymbol{F})$, as well as in the fraction of $D M 20^{+}$cells within the whole 0 lig2 ${ }^{+}$OL population $(15 \mathrm{dpl}, \boldsymbol{H})$ is observed in callosal regions of Ad-mHip compared with Ad-Control animals. $\mathbf{I}-\mathbf{L}$, LFB staining $(\boldsymbol{I})$ and MBP expression $(\boldsymbol{K})$ are shown in the demyelinated corpus callosum at $15 \mathrm{dpl}$ in Ad-mHip and Ad-control mice. Larger lesion areas and lower MBP expression are observed in Ad-mHip versus control animals. $J, L$, Quantifications of demyelinated areas and $M B P^{+}$cell density in Ad-mHip and Ad-Control mice at 5, 10, and 15 dpl. Values are the mean \pm SEM of five animals in each group. cc, Corpus callosum; $\left(X\right.$, cerebral cortex. Scale bars: I, $200 \mu \mathrm{m} ; \boldsymbol{C}, \boldsymbol{F}, \boldsymbol{K}, 50 \mu \mathrm{m} .{ }^{*} p<0.05 ;{ }^{* *} p<0.01 ;{ }^{* * *} p<0.001$.

mice (Wang et al., 2008). Despite the presence of a high number of $\mathrm{GFAP}^{+}$reactive astrocytes in the lesion as expected, we did not observe coexpression of Shh with GFAP suggesting either the activation of different populations of reactive astrocytes in the gray and white matter or differences in secreted pro-inflammatory substances according to the type of injury or lesion site. Thus, our results clearly differ from these reports and identify the OL lineage as the source of Shh in LPCdemyelinating lesions.

In agreement with Shh expression starting very early during the repair phase, the major positive mediators of Shh signaling were also found upregulated in the lesion. Consistent with a po- 
tential effect of Shh signaling on both OPCs and mature OLs, we clearly identified the Olig2 ${ }^{+}$cells as the main cell population in which Gli1, the readout of Shh signaling, is upregulated. A subset of Olig2 ${ }^{+}$cells also express Smo. Therefore, these cells can be considered as Shh-responding cells via the canonical Shh pathway, which is based on a series of repressive interactions culminating in Gli-mediated transcriptional regulation of various processes (Jenkins, 2009). However, $>50 \%$ of Smo-expressing cells in the lesion are microglia, clearly identifying this population as a direct target of Shh signaling. Although Smo has not been characterized as an Shh target gene, Smo is upregulated in motoneurons after facial nerve axotomy and its pharmacological blockade was shown to prevent neuronal cell death in this model (Akazawa et al., 2004). Though we cannot exclude a direct transcriptional effect of Shh on Gli2 during remyelination, other signaling pathways might be involved in this effect such as TGF- $\beta 1$, which was reported to be expressed upon demyelination and to regulate Gli2 transcription (Dennler et al., 2007; Franklin and ffrench-Constant, 2008).

In the adult rodent brain, Shh is a mitogen for adult progenitors residing in the dentate gyrus (Lai et al., 2003) and in the cerebral cortex (Loulier et al., 2006) but not for those residing in the SVZ. Shh modulates neuroblast exit from the SVZ through its chemoattractive activity (Angot et al., 2008). A protective effect of Shh was also observed upon adenoviral vector-mediated delivery of Shh into the rat brain, which prevents the neurotoxic effect induced by the neurotoxin 6-hydroxydopamine on dopaminergic neurons (Dass et al., 2005). Since we took advantage of various protocols allowing Shh overexpression before or after the triggering of the lesion, we were able to undoubtedly relate Shh repairing activities to either the survival or regeneration of myelinating OLs. Shh may increase OL proliferation and differentiation steps, both part of the yet effective ongoing repair process naturally occurring in the focal demyelination model, and/or protect the OLs and thus increase their survival upon the LPCmediated insult.

In this study, we provide evidence that blocking the Shh signaling pathway by Hip, its physiological antagonist, results in a decrease of OPC proliferation and differentiation preventing tissue repair. Our experiments suggest that Hip, when delivered before the LPC-induced lesion, antagonizes Shh produced during the acute phase of the lesion, and demonstrate that the negative regulation of the Shh signaling pathway plays a major role in tissue repair. Thus, these data argue for an important role of the Shh signaling pathway in myelin repair. Further work is needed to delineate the potential roles of the various actors of the pathway and, for example, to characterize the effects of Smo antagonists on lesion repair since they are widely available and already in clinic for the treatment of various cancers (Scales and de Sauvage, 2009; Ruat et al., 2012).

Shh effects on OL differentiation might be direct or indirect involving the regulation of pathways implicated in OPC differentiation as, for instance, the inhibition of negative regulators such as LINGO-1 (Mi et al., 2007), Notch (Zhang et al., 2009), BMP (Cate et al., 2010), and Wnt signals (Fancy et al., 2009; Fancy et al., 2011b; Huang and Franklin, 2011) or the modulation of positive regulators such as the retinoid $\mathrm{X}$ receptors (Huang et al., 2011). It is worthwhile to note that the zebrafish Shh gene was shown to be positively regulated by the retinoid $\mathrm{X}$ receptor and retinoic acid receptor heterodimers (Chang et al., 1997) and that deficiency of retinoic acid synthesis in retinaldehyde dehydrogenase 2 knock-out mouse mutant is associated with Shh downregulation in the forebrain (Ribes et al., 2009). If we consider the role established for Shh in the specification of the OL lineage during development, our data support the recapitulation hypothesis of myelin regeneration, meaning that several mechanisms are common for developmental and repairing myelination (Dubois-Dalcq et al., 2008; Franklin and ffrench-Constant, 2008; Fancy et al., 2010, 2011a). Moreover, recent studies have shown how Shh could enhance differentiation by decreasing histone acetylation, which leads to chromatin condensation in cultured OPCs (Wu et al., 2012). Overall, these results agree with the proposed involvement of Shh in the beneficial effects of triiodothyronine (Harsan et al., 2008) and interferon- $\beta$ (Mastronardi et al., 2004) previously reported in different demyelination models. In addition, we have observed that Shh overexpression decreases the astrogliosis and macrophage infiltration detected throughout the lesion. According to the animal model and the acute or chronic features of the demyelination, a dual role has been attributed to reactive astrocytes and macrophages, which both participate in degeneration/demyelination, and create a permissive environment for remyelination (Williams et al., 2007; Franklin and ffrench-Constant, 2008). Although our data do not allow us to definitely raise any conclusion on the beneficial or detrimental effect of Shh overexpression on inflammation and astrogliosis, the resulting global effect favors the repair. Shh may target the subsets of microglial and astroglial cells, which are deleterious and consequently counterbalance inflammatory events induced during lesion formation. This could be related to the endogenous immune quiescent role of the Shh pathway, which was previously shown at the level of the blood-brain barrier by protecting the CNS against entry of pro-inflammatory lymphocytes (Alvarez et al., 2011). The precise identification of the Shh-responding microglia and the associated secreted cytokines would require further investigation.

One of the strategies aimed at enhancing myelination in multiple sclerosis is to increase the differentiation of endogenous OPCs into mature OLs by acting on pathways that limit OPC differentiation (Mi et al., 2009). More recently, a small molecule agonist of the retinoid $\mathrm{X}$ receptor has been shown to increase the remyelination of axons in demyelinated cerebellar slice culture and aged rats (Huang et al., 2011). Chemical agonists of $\mathrm{Smo}$ are available and show great promise in regenerative medicine (Heretsch et al., 2010; Ruat et al., 2012). Since Smo is upregulated in remyelinating brain lesions, it represents an interesting target to favor the process of myelin repair.

\section{References}

Akazawa C, Tsuzuki H, Nakamura Y, Sasaki Y, Ohsaki K, Nakamura S, Arakawa Y, Kohsaka S (2004) The upregulated expression of sonic hedgehog in motor neurons after rat facial nerve axotomy. J Neurosci 24: 7923-7930. CrossRef Medline

Alvarez JI, Dodelet-Devillers A, Kebir H, Ifergan I, Fabre PJ, Terouz S, Sabbagh M, Wosik K, Bourbonnière L, Bernard M, van Horssen J, de Vries HE, Charron F, Prat A (2011) The Hedgehog pathway promotes bloodbrain barrier integrity and CNS immune quiescence. Science 334:17271731. CrossRef Medline

Amankulor NM, Hambardzumyan D, Pyonteck SM, Becher OJ, Joyce JA Holland EC (2009) Sonic hedgehog pathway activation is induced by acute brain injury and regulated by injury-related inflammation. J Neurosci 29:10299-10308. CrossRef Medline

Angot E, Loulier K, Nguyen-Ba-Charvet KT, Gadeau AP, Ruat M, Traiffort E (2008) Chemoattractive activity of sonic hedgehog in the adult subventricular zone modulates the number of neural precursors reaching the olfactory bulb. Stem Cells 26:2311-2320. CrossRef Medline

Arnett HA, Fancy SP, Alberta JA, Zhao C, Plant SR, Kaing S, Raine CS, Rowitch DH, Franklin RJ, Stiles CD (2004) bHLH transcription factor Olig1 is required to repair demyelinated lesions in the CNS. Science 306: 2111-2115. CrossRef Medline 
Ayoub AE, Salm AK (2003) Increased morphological diversity of microglia in the activated hypothalamic supraoptic nucleus. J Neurosci 23:77597766. Medline

Becher OJ, Hambardzumyan D, Fomchenko EI, Momota H, Mainwaring L, Bleau AM, Katz AM, Edgar M, Kenney AM, Cordon-Cardo C, Blasberg RG, Holland EC (2008) Gli activity correlates with tumor grade in platelet-derived growth factor-induced gliomas. Cancer Res 68:22412249. CrossRef Medline

Benraiss A, Chmielnicki E, Lerner K, Roh D, Goldman SA (2001) Adenoviral brain-derived neurotrophic factor induces both neostriatal and olfactory neuronal recruitment from endogenous progenitor cells in the adult forebrain. J Neurosci 21:6718-6731. Medline

Cate HS, Sabo JK, Merlo D, Kemper D, Aumann TD, Robinson J, Merson TD, Emery B, Perreau VM, Kilpatrick TJ (2010) Modulation of bone morphogenic protein signalling alters numbers of astrocytes and oligodendroglia in the subventricular zone during cuprizone-induced demyelination. J Neurochem 115:11-22. CrossRef Medline

Chang BE, Blader P, Fischer N, Ingham PW, Strähle U (1997) Axial (HNF3beta) and retinoic acid receptors are regulators of the zebrafish sonic hedgehog promoter. EMBO J 16:3955-3964. CrossRef Medline

Charytoniuk D, Porcel B, Rodríguez Gomez J, Faure H, Ruat M, Traiffort E (2002a) Sonic Hedgehog signalling in the developing and adult brain. J Physiol Paris 96:9-16. CrossRef Medline

Charytoniuk D, Traiffort E, Hantraye P, Hermel JM, Galdes A, Ruat M (2002b) Intrastriatal sonic hedgehog injection increases Patched transcript levels in the adult rat subventricular zone. Eur J Neurosci 16:23512357. CrossRef Medline

Chuang PT, McMahon AP (1999) Vertebrate Hedgehog signalling modulated by induction of a Hedgehog-binding protein. Nature 397:617-621. CrossRef Medline

Coulombe J, Traiffort E, Loulier K, Faure H, Ruat M (2004) Hedgehog interacting protein in the mature brain: membrane-associated and soluble forms. Mol Cell Neurosci 25:323-333. CrossRef Medline

Dass B, Iravani MM, Huang C, Barsoum J, Engber TM, Galdes A, Jenner P (2005) Sonic hedgehog delivered by an adeno-associated virus protects dopaminergic neurones against 6-OHDA toxicity in the rat. J Neural Transm 112:763-778. CrossRef Medline

Dennler S, André J, Alexaki I, Li A, Magnaldo T, ten Dijke P, Wang XJ, Verrecchia F, Mauviel A (2007) Induction of sonic hedgehog mediators by transforming growth factor-beta: Smad3-dependent activation of Gli2 and Gli1 expression in vitro and in vivo. Cancer Res 67:6981-6986. CrossRef Medline

Dubois-Dalcq M, Williams A, Stadelmann C, Stankoff B, Zalc B, Lubetzki C (2008) From fish to man: understanding endogenous remyelination in central nervous system demyelinating diseases. Brain 131:1686-1700. CrossRef Medline

Fancy SP, Baranzini SE, Zhao C, Yuk DI, Irvine KA, Kaing S, Sanai N, Franklin RJ, Rowitch DH (2009) Dysregulation of the Wnt pathway inhibits timely myelination and remyelination in the mammalian CNS. Genes Dev 23:1571-1585. CrossRef Medline

Fancy SP, Kotter MR, Harrington EP, Huang JK, Zhao C, Rowitch DH, Franklin RJ (2010) Overcoming remyelination failure in multiple sclerosis and other myelin disorders. Exp Neurol 225:18-23. CrossRef Medline

Fancy SP, Chan JR, Baranzini SE, Franklin RJ, Rowitch DH (2011a) Myelin regeneration: a recapitulation of development? Annu Rev Neurosci 34: 21-43. CrossRef Medline

Fancy SP, Harrington EP, Yuen TJ, Silbereis JC, Zhao C, Baranzini SE, Bruce CC, Otero JJ, Huang EJ, Nusse R, Franklin RJ, Rowitch DH (2011b) Axin2 as regulatory and therapeutic target in newborn brain injury and remyelination. Nat Neurosci 14:1009-1016. CrossRef Medline

Franklin RJ, ffrench-Constant C (2008) Remyelination in the CNS: from biology to therapy. Nat Rev Neurosci 9:839-855. CrossRef Medline

Fuccillo M, Joyner AL, Fishell G (2006) Morphogen to mitogen: the multiple roles of hedgehog signalling in vertebrate neural development. Nat Rev Neurosci 7:772-783. CrossRef Medline

Harsan LA, Steibel J, Zaremba A, Agin A, Sapin R, Poulet P, Guignard B, Parizel N, Grucker D, Boehm N, Miller RH, Ghandour MS (2008) Recovery from chronic demyelination by thyroid hormone therapy: myelinogenesis induction and assessment by diffusion tensor magnetic resonance imaging. J Neurosci 28:14189-14201. CrossRef Medline
Heretsch P, Tzagkaroulaki L, Giannis A (2010) Modulators of the hedgehog signaling pathway. Bioorg Med Chem 18:6613-6624. CrossRef Medline

Horn A, Palumbo K, Cordazzo C, Dees C, Akhmetshina A, Tomcik M, Zerr P, Avouac J, Gusinde J, Zwerina J, Roudaut H, Traiffort E, Ruat M, Distler O, Schett G, Distler JH (2012) Hedgehog signaling controls fibroblast activation and tissue fibrosis in systemic sclerosis. Arthritis Rheum 64:27242733. CrossRef Medline

Huang JK, Franklin RJ (2011) Regenerative medicine in multiple sclerosis: identifying pharmacological targets of adult neural stem cell differentiation. Neurochem Int 59:329-332. Medline

Huang JK, Jarjour AA, Nait Oumesmar B, Kerninon C, Williams A, Krezel W, Kagechika H, Bauer J, Zhao C, Evercooren AB, Chambon P, ffrenchConstant C, Franklin RJ (2011) Retinoid X receptor gamma signaling accelerates CNS remyelination. Nat Neurosci 14:45-53. CrossRef Medline

Hughes DC, Allen J, Morley G, Sutherland K, Ahmed W, Prosser J, Lettice L, Allan G, Mattei MG, Farrall M, Hill RE (1997) Cloning and sequencing of the mouse Gli2 gene: localization to the Dominant hemimelia critical region. Genomics 39:205-215. CrossRef Medline

Jenkins D (2009) Hedgehog signalling: emerging evidence for noncanonical pathways. Cell Signal 21:1023-1034. CrossRef Medline

Lai K, Kaspar BK, Gage FH, Schaffer DV (2003) Sonic hedgehog regulates adult neural progenitor proliferation in vitro and in vivo. Nat Neurosci 6:21-27. CrossRef Medline

Le Bras B, Chatzopoulou E, Heydon K, Martínez S, Ikenaka K, Prestoz L, Spassky N, Zalc B, Thomas JL (2005) Oligodendrocyte development in the embryonic brain: the contribution of the plp lineage. Int J Dev Biol 49:209-220. CrossRef Medline

Loulier K, Ruat M, Traiffort E (2006) Increase of proliferating oligodendroglial progenitors in the adult mouse brain upon Sonic hedgehog delivery in the lateral ventricle. J Neurochem 98:530-542. CrossRef Medline

Machold R, Hayashi S, Rutlin M, Muzumdar MD, Nery S, Corbin JG, GritliLinde A, Dellovade T, Porter JA, Rubin LL, Dudek H, McMahon AP, Fishell G (2003) Sonic hedgehog is required for progenitor cell maintenance in telencephalic stem cell niches. Neuron 39:937-950. CrossRef Medline

Magalon K, Zimmer C, Cayre M, Khaldi J, Bourbon C, Robles I, Tardif G, Viola A, Pruss RM, Bordet T, Durbec P (2012) Olesoxime accelerates myelination and promotes repair in models of demyelination. Ann Neurol 71:213-226. CrossRef Medline

Mastronardi FG, Min W, Wang H, Winer S, Dosch M, Boggs JM, Moscarello MA (2004) Attenuation of experimental autoimmune encephalomyelitis and nonimmune demyelination by IFN-beta plus vitamin B12: treatment to modify notch-1/sonic hedgehog balance. J Immunol 172: 6418-6426. Medline

Menn B, Garcia-Verdugo JM, Yaschine C, Gonzalez-Perez O, Rowitch D, Alvarez-Buylla A (2006) Origin of oligodendrocytes in the subventricular zone of the adult brain. J Neurosci 26:7907-7918. CrossRef Medline

Mi S, Hu B, Hahm K, Luo Y, Kam Hui ES, Yuan Q, Wong WM, Wang L, Su H, Chu TH, Guo J, Zhang W, So KF, Pepinsky B, Shao Z, Graff C, Garber E, Jung V, Wu EX, Wu W (2007) LINGO-1 antagonist promotes spinal cord remyelination and axonal integrity in MOG-induced experimental autoimmune encephalomyelitis. Nat Med 13:1228-1233. CrossRef Medline

Mi S, Miller RH, Tang W, Lee X, Hu B, Wu W, Zhang Y, Shields CB, Zhang Y, Miklasz S, Shea D, Mason J, Franklin RJ, Ji B, Shao Z, Chédotal A, Bernard F, Roulois A, Xu J, Jung V, et al. (2009) Promotion of central nervous system remyelination by induced differentiation of oligodendrocyte precursor cells. Ann Neurol 65:304-315. CrossRef Medline

Nait-Oumesmar B, Decker L, Lachapelle F, Avellana-Adalid V, Bachelin C, Baron-Van Evercooren A (1999) Progenitor cells of the adult mouse subventricular zone proliferate, migrate and differentiate into oligodendrocytes after demyelination. Eur J Neurosci 11:4357-4366. CrossRef Medline

Nishiyama A, Komitova M, Suzuki R, Zhu X (2009) Polydendrocytes (NG2 cells): multifunctional cells with lineage plasticity. Nat Rev Neurosci 10: 9-22. CrossRef Medline

Pascual O, Traiffort E, Baker DP, Galdes A, Ruat M, Champagnat J (2005) Sonic hedgehog signalling in neurons of adult ventrolateral nucleus tractus solitarius. Eur J Neurosci 22:389-396. CrossRef Medline

Ribes V, Le Roux I, Rhinn M, Schuhbaur B, Dollé P (2009) Early mouse 
caudal development relies on crosstalk between retinoic acid, Shh and Fgf signalling pathways. Development 136:665-676. CrossRef Medline

Ruat M, Roudaut H, Ferent J, Traiffort E (2012) Hedgehog trafficking, cilia and brain functions. Differentiation 83:S97-S104. CrossRef Medline

Scales SJ, de Sauvage FJ (2009) Mechanisms of Hedgehog pathway activation in cancer and implications for therapy. Trends Pharmacol Sci 30: 303-312. CrossRef Medline

Sofroniew MV (2009) Molecular dissection of reactive astrogliosis and glial scar formation. Trends Neurosci 32:638-647. CrossRef Medline

Spassky N, Olivier C, Cobos I, LeBras B, Goujet-Zalc C, Martínez S, Zalc B, Thomas JL (2001) The early steps of oligodendrogenesis: insights from the study of the plp lineage in the brain of chicks and rodents. Dev Neurosci 23:318-326. CrossRef Medline

Thien H, Büscher D, Rüther U (1996) Cloning and sequence analysis of the murine Gli3 cDNA. Biochim Biophys Acta 1307:267-269. CrossRef Medline

Traiffort E, Charytoniuk D, Watroba L, Faure H, Sales N, Ruat M (1999) Discrete localizations of hedgehog signalling components in the developing and adult rat nervous system. Eur J Neurosci 11:3199-3214. CrossRef Medline

Traiffort E, Moya KL, Faure H, Hässig R, Ruat M (2001) High expression and anterograde axonal transport of aminoterminal sonic hedgehog in the adult hamster brain. Eur J Neurosci 14:839-850. CrossRef Medline

Traiffort E, Angot E, Ruat M (2010) Sonic Hedgehog signaling in the mammalian brain. J Neurochem 113:576-590. CrossRef Medline

Wang Y, Imitola J, Rasmussen S, O'Connor KC, Khoury SJ (2008) Paradoxical dysregulation of the neural stem cell pathway sonic hedgehog-Glil in autoimmune encephalomyelitis and multiple sclerosis. Ann Neurol 64:417-427. CrossRef Medline

Williams A, Piaton G, Lubetzki C (2007) Astrocytes-friends or foes in multiple sclerosis? Glia 55:1300-1312. CrossRef Medline

Wu M, Hernandez M, Shen S, Sabo JK, Kelkar D, Wang J, O’Leary R, Phillips GR, Cate HS, Casaccia P (2012) Differential modulation of the oligodendrocyte transcriptome by sonic hedgehog and bone morphogenetic protein 4 via opposing effects on histone acetylation. J Neurosci 32:6651-6664. CrossRef Medline

Yoon SO, Lois C, Alvirez M, Alvarez-Buylla A, Falck-Pedersen E, Chao MV (1996) Adenovirus-mediated gene delivery into neuronal precursors of the adult mouse brain. Proc Natl Acad Sci U S A 93:11974-11979. CrossRef Medline

Zhang Y, Argaw AT, Gurfein BT, Zameer A, Snyder BJ, Ge C, Lu QR, Rowitch DH, Raine CS, Brosnan CF, John GR (2009) Notch1 signaling plays a role in regulating precursor differentiation during CNS remyelination. Proc Natl Acad Sci U S A 106:19162-19167. CrossRef Medline 